\title{
Geschlechtergerechtigkeit im Wettbewerb der Regulierungsmodelle
}

- Wege zur tatsächlichen Durchsetzung der Gleichberechtigung in Führungspositionen der Wirtschaft -

Michael Grünberger"

I. Problemstellung

II. Die Geschlechterverteilung in deutschen Vorständen und Aufsichtsräten

III. Geschlechtergerechtigkeit oder Diversity?.

1. Geschlechtergerechtigkeit .......

2. Diversity ..................... 8

a) Begriff $\ldots \ldots \ldots \ldots \ldots \ldots \ldots \ldots$

b) Verwurzelung im U.S.-amerikanischen Gleichheitsdiskurs

c) Business Case für Diversität?

(1) Ein Zusammenhang zwischen Gender Diversity und dem Unternehmensinteresse?

(2) Diversity in der Genderfalle...

IV. Regulierungsansätze zur Erhöhung des Frauenanteils in Führungspositionen

1. Selbstregulierung....

a) Präferenzautonomie des Verbandes

b) Ein Problem tatsächlicher Gleichheit ...

c) Freiwillige Selbstverpflichtung.

d) Rechtfertigungsbedarf der Selbstregulierung
1 5 5 8 8
2. Staatliche Regulierung...........

a) Europäische Regelungsvorbilder..................... 24

b) Regelungsvorschläge in Deutschland 25

c) Instrumentalisierung des Verbandsrechts?............. 26

d) Regulierungsversagen?...... 28

3. Regulierte Selbstregulierung.... 30

a) Deutscher Corporate Governance Kodex.......... 30

(1) „Rechtsnatur“ von Empfehlungen des DCGK.......... 30

(2) Diversity-Empfehlungen.... 33

aa) Führungspositionen unterhalb des Vorstandes ........ 33

bb) Besetzung des Vorstandes . . 34

cc) Besetzung des Aufsichtsrats ...................... 34

dd) Durchsetzung ............. 36

(3) Persistenz statussichernder Ungleichbehandlung....... 38

b) „FlexiQuote“............. 40

(1) Regulierte Selbstregulierung als Mehrstufenmodell...... 40

(2) Eingeschränktes Misstrauensvotum gegenüber dem DCGK .................. 41

4. Ein Kombinationsmodell....... 43 V. Ausblick ...................... 44

\section{Problemstellung}

Die Forderung nach Gleichberechtigung der Geschlechter ist Ausdruck des fundamentalen Gleichheitsversprechens demokratischer Ordnungen, wonach jeder Mensch unabhängig von bestimmten persönlichen Merkmalen gleiche Freiheiten in der Gesellschaft haben soll. Das Prinzip „Gleichbehandlung“ als Grundidee der modernen politischen Philosophie erlaubt es, Ungleichverteilungen bei der Ausübung von Freiheitsmöglichkeiten und der Verteilung gesellschaftlicher Machtpositionen

* Priv.-Doz. Dr. Michael Grünberger, LL.M. (NYU) ist am Institut für Gewerblichen Rechtsschutz und Urheberrecht der Universität zu Köln tätig. 
$\mathrm{zu}$ erkennen und zu hinterfragen. ${ }^{1} \mathrm{Zu}$ diesen Machtpositionen in der Gesellschaft zählen neben den hochrangigen Funktionärsebenen im politischen System auch Führungspositionen im Wirtschaftssystem. Die statistisch belegbaren Unterschiede zwischen den Geschlechtern bei der Besetzung dieser Positionen ${ }^{2}$ werden mittlerweile im gesamten politischen Spektrum als Problem wahrgenommen. Das gilt insbesondere für Vorstände und Aufsichtsräte deutscher Aktiengesellschaften (dazu unten II). Diese Statistiken haben eine erhebliche politische Funktion: Sie machen das Ausmaß der Ungleichverteilung von Positionen privater Macht sichtbar. Sie verdeutlichen, dass Frauen aufgrund vorhandener oder ihnen zugeschriebener Eigenschaften im Wirtschaftssystem nicht als Individuum, sondern als Mitglied der „Gruppe Frau“ wahrgenommen und als solches offensichtlich unterschiedlich behandelt werden. Dadurch entsteht Mobilisierungspotential von und für Frauen, um die ungleiche Geschlechterverteilung von Aufsichtsratspositionen als politisches Problem zu thematisieren. ${ }^{3}$ Diese Mobilisierung hat dazu geführt, dass das Geschlechterverhältnis bei der Besetzung von Vorständen und Aufsichtsräten von Aktiengesellschaften zum Gegenstand öffentlicher Debatten geworden ist. Zugespitzt formuliert: Die Besetzung der Organe privater Gesellschaften ist keine private Angelegenheit des einzelnen Verbandes, sondern eine Angelegenheit von öffentlichem Interesse. ${ }^{4}$

Nach meinem Eindruck besteht Konsens, den Anteil von Frauen in Führungspositionen zu erhöhen. Gestritten wird über den einzuschlagenden Weg: ${ }^{5}$ Genügt es, auf den Markt und freiwillige Selbstverpflichtungen der Unternehmen zu setzen? Soll man abwarten, wie die Diversity-Empfehlungen und die dort vorgesehene „angemessene Berücksichtigung von Frauen“ im Deutschen Corporate Governance Kodex $(\mathrm{DCGK})^{6}$ fruchten? Oder muss man gesetzlich intervenieren und wenn ja, wie: Genügt eine gesetzlich verpflichtende Selbstverpflichtung („FlexiQuote“) oder muss das Recht einen Mindestanteil von Frauen in Aufsichtsräten vorschreiben („Einheitsquote“)? Diese drei Lösungswege sind Anwendungsfälle unterschiedlicher Regulierungsstrategien: Markt und freiwillige Selbstverpflichtung sind Beispiele einer Selbstregulierung, die Einheitsquote ist staatliche Regulierung par excellence, während die

1 Dazu ausführlich Grünberger, Personale Gleichheit. Der Grundsatz der Gleichbehandlung im Zivilrecht. Habilitationsschrift, Köln 2011 (zugreifbar unter http://papers.ssrn.com/sol3/papers.cfm?abstract_id=1895366), $1 \mathrm{ff}, 926 \mathrm{ff}$.

2 Siehe die Untersuchung von Holst/Busch, DIW Führungskräfte-Monitor 2010, http://www.diw.de/documents/publikationen/73/diw_01.c.358490.de/diwkompakt_2010-056.pdf (zuletzt besucht: 20.8.2011), $21 \mathrm{ff}$

3 Siehe dazu auf nationaler Ebene die Aktion „Aktionärinnen fordern Gleichberechtigung “ des Deutschen Juristinnenbundes (http://www.djb.de/Projekt_HV/), den Verein „FidAR - Frauen in die Aufsichtsräte e.V.“ (http://www.fidar.de/) und die Initiative „Nürnberger Resolution“ (http://www.nürnberger-resolution.de/index.htm).

4 Zum hier verwendeten Begriff der öffentlichen Kommunikation siehe Habermas, Faktizität und Geltung, 4. Aufl., 1994, $434 \mathrm{ff}$.

5 Instruktiv der Überblick bei Bachmann, ZIP 2011, $1131 \mathrm{ff}$ und Langenbucher, DB 2010, $43 \mathrm{ff}$.

6 http://www.corporate-governance-code.de/index.html. 
Empfehlungen im DCGK und die „FlexiQuote“ Formen „regulierter Selbstregulierung" sind (dazu unten IV).

Die damit angestrebte Steigerung des Frauenanteils lässt sich im Wesentlichen auf zwei Argumente stützen:7 (1.) „Geschlechtergerechtigkeit“ und (2.) dem Business Case. Geschlechtergerechtigkeit verlangt die Gleichberechtigung von Frauen und Männern in allen gesellschaftlichen Bereichen als moralisches, gesellschaftspolitisches und verfassungsrechtliches Gebot. Das ökonomische Argument basiert auf einem Wettbewerbsverständnis, wonach eine Kultur der Vielfalt (Diversity) in Unternehmen und ein damit verbundener höherer Frauenanteil in den Führungsetagen einen realen Wettbewerbsvorteil für die Unternehmen bedeutet, und der These, dass ein (auch) mit Frauen besetzter Aufsichtsrat wichtiger Bestandteil einer guten Corporate Governance im Unternehmen ist. Welche der drei Regulierungsstrategien im Wirtschaftssystem fruchtet, hängt nach meiner Auffassung davon ab, auf welchen Begründungsansatz sie sich stützt. Der Disput über die Diversity-Empfehlungen des DCGK illustriert das Problem: Nach Auffassung von Daniela Weber-Rey, einem Mitglied der Regierungskommission DCGK, war und ist eine gesellschaftspolitische Besserstellung von Frauen „nie Ziel der Empfehlungen gewesen“. ${ }^{8}$ Dagegen geht es nach Peter O. Mülbert bei der Erhöhung des Frauenanteils im Kern um eine Instrumentalisierung der Corporate Governance für nicht mehr dazu zählende, primär allgemein gesellschaftspolitische Zielsetzungen. ${ }^{9}$ Beide Positionen teilen denselben Ausgangspunkt: Ausschlaggebend ist der im Wirtschaftssystem relevante Code: das Geld. Diversity kann danach an die Operationen im Wirtschaftssystem nur anschließen, wenn es die Sprache des Geldes spricht. Bei Diversity, so Weber-Rey, gehe es um Qualitätssteigerungen, um den umfangreichen Aufgaben eines Aufsichtsrats und damit dem Unternehmensinteresse gerecht werden zu können. ${ }^{10}$ Diversity, so sekundiert Mülbert, sei nur insofern geboten „als die Gesellschaft hiervon einen Gewinn hat". ${ }^{11}$ Gestritten wird also darüber, ob Diversity und die Erhöhung des Frauenanteils in der Eigenrationalität des Wirtschaftssystems anschlussfähig sind. Die einen bejahen das und verweisen auf wissenschaftliche Studien ${ }^{12}$ und den common sen$s e,{ }^{13}$ die anderen sehen darin ein trojanisches Pferd, das das Aktienrecht mit gesellschaftspolitischen Vorstellungen überfrachte und einer juristischen Analyse kaum zugänglich sei. ${ }^{14}$

7 Vgl. dazu auch Langenbucher, JZ 2011,1038 f.

8 Weber-Rey/Handt, NZG 2011, 1, 2.

9 Mülbert, ZHR (174) 2010, 375, 380, 382, 384.

10 Weber-Rey/Handt, NZG 2011, 1, 2.

11 Mülbert, ZHR (174) 2010, 375, 382.

12 Dazu unten III 2 c) (1).

13 Dauner-Lieb, DB 2010, 45, 46.

14 Vgl. Fleischer, ZGR 2011, 155, 157. 
Die wirklich spannende Frage lautet aber, ob sich Diversity mit Geschlechtergerechtigkeit produktiv verbinden lässt. Im politischen System wird das bejaht. Die - mittlerweile abgelehnten - Gesetzesentwürfe der Fraktion BÜNDNIS 90/Die Grünen ${ }^{15}$ und des Landes NRW ${ }^{16}$ zu einer Einheitsquote gehen davon aus, dass mit der Anhebung des Frauenanteils in Aufsichtsräten „einerseits in gleichstellungspolitischer Hinsicht ein gleichberechtigter und chancengleicher Zugang beider Geschlechter zu den bedeutsamen Schlüsselpositionen im Wirtschaftsleben geschaffen und andererseits die mit einer geschlechtsheterogenen Besetzung der Aufsichtsräte verbundenen positiven Effekte für die Unternehmen und die Wirtschaft insgesamt genutzt werden “. ${ }^{17}$ Ganz ähnlich ist die Einschätzung der EU-Kommission. ${ }^{18}$ Offensichtlich ist Diversity ein Begriff, der sich zur strukturellen Kopplung ${ }^{19}$ des Wirtschaftssystems mit dem politischen und dem Rechtssystem eignet.

\section{Die Geschlechterverteilung in deutschen Vorständen und Aufsichtsräten}

Es gibt reichlich Datenmaterial zur Geschlechterverteilung in den Organen deutscher Aktiengesellschaften. ${ }^{20} \mathrm{Im}$ Jahr 2009 gab es nur eine Frau in den Vorständen der DAX30-Unternehmen, im Jahr 2010 waren es immerhin 4 von 182. ${ }^{21}$ Das ergibt einen Anteil von 2,2 \%. Deutlich höher ist der Anteil von Frauen in den Aufsichts-

15 Entwurf eines Gesetzes zur geschlechtergerechten Besetzung von Aufsichtsräten der Fraktion BÜNDNIS 90/Die Grünen, BT-Drs. 17/3296, S. 8 f [im Folgenden Entwurf Grüne]; im Rechtsausschuss abgelehnt, s. Beschlussempfehlung und Bericht, BT-Drs. 17/6527, Ablehnung nach zweiter und dritter Beratung in der 147. Sitzung des Bundestags am 2.12.2011, abrufbar unter: http://www.bundestag.de/ dokumente/protokolle/amtlicheprotokolle/2011/ap17147.html. Der Entschließungsantrag der Fraktion BÜNDNIS 90/Die Grünen „Gleichberechtigte Teilhabe von Frauen in Führungspositionen umsetzen“v. 30.11.2011, BT-Drs. 17/7953 ist in derselben Sitzung in die Ausschüsse überwiesen worden.

16 Entwurf eines Gesetzes zur Förderung der Gleichberechtigung von Frauen und Männern in Aufsichtsräten börsennotierter Unternehmen (FöGAbUG), eingebracht vom Land NRW, BR-Drs. 87/11, S. $15 \mathrm{ff}$ [im Folgenden Entwurf NRW]; vom Bundesrat am 25.11.2011 abgelehnt, BR-Drs. 87/11 (B).

17 Entwurf NRW (Fn. 16), S. 15 f.

18 Vgl. die „Strategie für die Gleichstellung von Frauen und Männern 2010-2015“ v.21.9.2010, KOM(2010) 491 endg., S. 8 und das Grünbuch Europäischer Corporate Governance-Rahmen, $\operatorname{KOM}(2011)$ 164/3, S. 7 f.

19 Zum Begriff Teubner, Steuerung durch plurales Recht. Oder: Wie die Politik den normativen Mehrwert der Geldzirkulation abschöpft, in: Zapf (Hrsg.), Die Modernisierung moderner Gesellschaften, Verhandlungen des 25. Deutschen Soziologentages, 1990, 528, 536 ff; Luhmann, Das Recht der Gesellschaft, 1993, $441 \mathrm{ff}$; Callies, Prozedurales Recht, 1999, $181 \mathrm{ff.}$

20 Vgl. dazu Holst/Busch, DIW Führungskräfte-Monitor 2010 (Fn. 2.), 55 ff; Holst/Wiemer, DIW Wochenbericht Nr.4, 2010, http://www.diw.de/documents/publikationen/73/diw_01.c.346402.de/ 10-4-1.pdf (zuletzt besucht: 21.8.2011), 2 ff; Institut für Unternehmensführung, Frauen in Führungspositionen - Status Quo in der deutschen Wirtschaft, 2010, http://www.ibu.uni-karlsruhe.de/ rd_download/100414_Zusammenfassung_Projektergebnis-se.pdf?PHPSESSID=84c37efc-

f276a784e4c5b657158e5229 (zuletzt besucht: 21.8.2011); Kersten, Projektauswertung, Aktionärinnen fordern Gleichberechtigung 2010, http://www.djb.de/Projekt_HV/Doku2010/ (zuletzt besucht: 21.8.2011), $21 \mathrm{ff}$; Weckes, Geschlechterverteilung in Vorständen und Aufsichtsräten, 2010, http:// www.boeckler.de/pdf/mbf_gender_2010.pdf (zuletzt besucht: 21.8.2011); Holst/Schimeta, DIW Wochenbericht Nr.3, 2011, http://www.diw.de/documents/publikationen/73/diw_01.c.366825.de/ 11-3-1.pdf (zuletzt besucht: 21.8.2011), 2 ff.

21 Holst/Schimeta, DIW Wochenbericht Nr. 3 (Fn. 20), 2, 5. 
räten dieser Unternehmen: 13,3 \% im Jahr 2009 bzw. 13,2 \% im Jahr 2010.22 Erweitert man die Datengrundlage auf 160 börsennotierte Unternehmen, die im DAX30, MDAX, SDAX und TECDAX zusammengefasst sind, lag der Anteil von weiblichen Aufsichtsräten Anfang 2010 bei 9,4\%. Unterscheidet man dabei allerdings zwischen Arbeitnehmer- und Anteilseignervertretern in mitbestimmten Unternehmen, ergibt sich ein deutlich differenzierteres Bild: Bei den Arbeitnehmervertretern stellen Frauen immerhin 18,1 \% der Aufsichtsratsmandate, während ihr Anteil bei den Anteilseignervertretern bei 3,8 \% verbleibt. ${ }^{23}$ Besonders brisant wird diese Zahl, wenn man sie mit dem Anteil von Frauen in den Vorständen dieser Unternehmen vergleicht: Er liegt bei $3 \%{ }^{24}$ Die politische Bedeutung dieser Zahlen erschließt sich im Vergleich mit anderen Parametern in Gesellschaft und Wirtschaft, bei denen das Geschlechterverhältnis im Wesentlichen ausgeglichen ist: So lag der Anteil von Frauen in der Bevölkerung Ende des Jahres 2010 bei 50,9\%; bezieht man ihn auf den Anteil der Erwerbstätigen lag er immerhin noch bei 45,7\% \%. ${ }^{25}$ Sehr aussagekräftig sind branchenspezifische Vergleiche, beispielsweise für den privaten und öffentlich-rechtlichen Banken und Sparkassensektor: ${ }^{26}$ Danach betrug der Anteil der Frauen unter den Beschäftigten 57,6 \% im Jahr 2010. In den Aufsichtsorganen betrugt der Frauenanteil dagegen nur mehr 16,3 \%, in der Vorstands- und obersten Leitungsebene sogar nur mehr 2,9\%. Das Ergebnis ist immer eindeutig: Der Anteil von Frauen in Vorstand oder Aufsichtsrat ist immer signifikant kleiner als der Anteil der Beschäftigen. Die Verteilung dieser wirtschaftlichen Machtpositionen unter den Geschlechtern wird als Ungleichverteilung wahrgenommen. Daraus entsteht ein Rechtfertigungsdruck. Die Politik gerät in Zugzwang.

\section{Geschlechtergerechtigkeit oder Diversity?}

\section{Geschlechtergerechtigkeit}

Aufgabe einer gleichheitsrechtlich konzipierten Theorie juristischer Gerechtigkeit ist es, die Beteiligung des „Anderen“ 27 in einer von Stereotypen geprägten Gesellschaft als Gleicher zu thematisieren. ${ }^{28}$ Sie sensibilisiert das Recht für die Ungleichheiten in den anderen Funktionssystemen der Gesellschaft, insbesondere der Wirtschaft. Das

22 Weckes, Geschlechterverteilung in Vorständen und Aufsichtsräten (Fn. 20), 4.

23 Weckes, Geschlechterverteilung in Vorständen und Aufsichtsräten (Fn. 20), 8.

24 Die Zahlen beruhen auf Weckes, Geschlechterverteilung in Vorständen und Aufsichtsräten (Fn.20), 14.

25 Die Berechnung beruht auf den Zahlen des Statistischen Bundesamts (Hrsg.), Mikrozensus 2010, http://www.destatis.de/jetspeed/portal/cms/Sites/destatis/Internet/DE/Content/Publikationen/Fachveroeffentlichungen/Arbeitsmarkt/Erwerbstaetige/StandEntwicklungErwerbstaetigkeit2010411107004,property=file.pdf, (zuletzt besucht am 30.9.2011), S. 12-14.

26 Zu den Daten siehe Holst/Schimeta, DIW Wochenbericht Nr. 3, 2011, http:/www.diw.de/documents/ publikationen/73/diw_01.c.366829.de/11-3-3.pdf (zuletzt besucht: 21.8.2011), 12.

27 Weiterführend zur Dichotomie Wir/Andere Fisahn, Rechtstheorie (37) 2006, 67 ff.

$28 \mathrm{Zu}$ den theoretischen Grundlagen dieser These Grünberger, Personale Gleichheit (Fn. 1), $926 \mathrm{ff}$. 
Recht muss sich entscheiden, ob es sich zur ungleichen Verteilung von Freiheitssphären im Wirtschaftssystem indifferent verhalten oder ob es „intervenieren“ soll. Soweit die Ungleichheit anhand des Geschlechts erfolgt, findet sich die Antwort seit 1949 in Art. 3 Abs. 2 GG: ${ }^{29}$ „Männer und Frauen sind gleichberechtigt. “ Das ist kein nicht-justiziabler Programmsatz sondern echte Rechtsnorm: ${ }^{30}$ „Die politische Frage, ob die in Art. 3 Abs. 2 und 3 genannten Ungleichheiten einen beachtlichen Grund für Differenzierungen im Recht abgeben - worüber erfahrungsgemäß verschiedene Meinungen möglich sind -, ist damit verfassungskräftig verneint." Damit verabschiedete das BVerfG die These, dass „der Geschlechtsunterschied heute noch als rechtlich erheblich anzusehen ist" ${ }^{31}$ Der Wortlaut von Art. 3 Abs. 2 S. 1 GG lässt zwei Fragen unbeantwortet: (1.) Wer ist Adressat des Gleichberechtigungsgebots? Nur der Staat (Art. 1 Abs. 3 GG) oder auch private Rechtssubjekte? Wenn man die Bindung auf Private erstreckt, stellt sich ein Konstruktionsproblem: ${ }^{32}$ Handelt es sich um eine unmittelbare, aus der Verfassung abgeleitete oder eine mittelbare über den Gesetzgeber mediatisierte Bindung?33 (2.) Beschränkt sich das Diskriminierungsverbot in Art. 3 Abs. 3 S. 1 GG und das Gleichberechtigungsgebot in Art. 3 Abs. 2 S. 1 GG auf eine formale Konzeption von Gleichheit oder erlauben sie auch eine materielle Konzeption? Ein materielles Verständnis erlaubt es dem Recht, an den Geschlechterunterschied von Personen anzuknüpfen, um dadurch tatsächliche Gleichberechtigung in sozialen Kontexten zu verwirklichen. Beide Fragen stellten sich sofort nach Inkrafttreten des GG. ${ }^{34}$ Die Antworten darauf kamen aber nicht aus Karlsruhe oder Bonn, sondern aus Luxemburg und Brüssel. In Deutschland folgte man dem zunächst nur widerwillig. ${ }^{35}$ Nach traditionellem Verständnis erschöpft sich Gleichberechtigung nämlich darin, dass Frauen und Männer die gleichen Rechte und Pflichten haben. Die Herstellung faktischer Gleichheit sei nicht Ziel des Gleichheitsgrundrechts. ${ }^{36}$ Dagegen folgt das BVerfG seit 1992 einer neuen Konzeption des Art. 3 Abs. 2 GG. ${ }^{37}$ Danach erstreckt die Norm das Gleichberechtigungsgebot „,auch auf die gesellschaftliche Wirklichkeit“. ${ }^{38}$ „Der Satz "Männer und Frauen sind gleichberechtigt" [...] zielt auf die Angleichung der Lebensverhältnisse. So müssen Frauen

29 Art. 3 Abs. 2 S. 2 GG wurde erst mit dem Gesetz zur Änderung des Grundgesetzes v. 27.10.1994, BGBl. I 3146, hinzugefügt.

30 Grundlegend BVerfGE 3, 225, $239 \mathrm{f}$.

31 BVerfGE 3, 225, $239 \mathrm{f}$.

32 Vgl. dazu Alexy, Theorie der Grundrechte, 1994, 480.

33 Siehe dazu vertiefend Grünberger, Personale Gleichheit (Fn. 1), $1027 \mathrm{ff}$ und zuletzt Sachs, ZG 2012 (Heft 1) unter II 1 a.

34 Zur Antwort des BAG unter seinem Präsidenten Nipperdey (BAGE 1, 258) siehe jetzt die Würdigung von Schmidt, Der lange Weg zur Gleichberechtigung, FS Heide Pfarr, 2010, 253.

35 Eingehend zur Entwicklung Grünberger, Personale Gleichheit (Fn. 1), 216 ff.

36 Vgl. di Fabio, AöR (122) 1997, 404, 407 ff; Gubelt in: v. Münch/Kunig, GG, 5. Aufl., Bd. I, 2000, Art. 3 Rn. 82; Starck in: v.Mangoldt/Klein/Starck, GG, 6. Aufl., Bd. I, 2010, Art. 3 Rn. 309.

37 Zur Entwicklung Sacksofsky in: Umbach/Clemens, GG, Bd. I, 2002, Art. 3 II, III Rn. 353 ff.

38 BVerfGE 85, 191, 207; BVerfGE 109, 64, 89. 
die gleichen Erwerbschancen haben wie Männer."39 Diese Neukonzeption beruht auf vier Pfeilern: (1.) Der Regelungsgehalt des Art. 3 Abs. 2 S. 1 GG geht über das formale Diskriminierungsverbot in Art. 3 Abs. 3 S. 1 GG hinaus. ${ }^{40}$ (2.) Art. 3 Abs. 2 S. 1 GG beinhaltet ein materielles Gleichberechtigungsgebot. Es ist auf die Verwirklichung der Gleichstellung der Frauen in der Gesellschaft angelegt. ${ }^{41}$ (3.) Den Staat trifft eine Schutzpflicht zugunsten der Frauen. ${ }^{42}$ Er muss sicherstellen, dass sie gleiche Erwerbschancen haben und in der Gesellschaft vorhandene Diskriminierungen von Frauen wirksam bekämpfen. (4.) Art. 3 Abs. 2 S. 1 und die zwischenzeitlich erfolgte „Klarstellung“43 in Art. 3 Abs. 2 S. 2 GG erlauben es dem Staat, begünstigende Regelungen zugunsten der Frauen zu treffen und damit an das Geschlecht als an sich verpöntes Merkmal anzuknüpfen, um bestehende Nachteile auszugleichen und dadurch zur Verwirklichung der Gleichstellung der Frauen beizutragen. ${ }^{44}$ In dieser Konzeption materieller Gleichheit fungiert Art. 3 Abs. 2 GG als Rechtfertigungsgrund einer formalen Ungleichbehandlung. ${ }^{45}$

Die Frage, ob der Staat die tatsächliche Durchsetzung der Gleichberechtigung von Frauen und Männern im Wirtschaftssystem zu fördern und auf die Beseitigung bestehender Nachteile hinzuwirken hat, ist wegen Art. 3 Abs. 2 GG also kein ausschließlich politisches, sondern auch ein rechtliches Gebot. Der Staat muss zur Förderung der tatsächlichen Durchsetzung der Gleichberechtigung aktiv werden. Bloße Untätigkeit genügt nicht mehr. ${ }^{46}$ Das „Ob“ steht also nicht mehr zur Disposition. ${ }^{47}$ Damit bildet Art. 3 Abs. 2 GG die gleichheitsrechtliche Legitimation von Maß-

39 BVerfGE 85, 191, 207 [Hervorhebungen hinzugefügt].

40 Näher zum Verhältnis Heun in: Dreier, GG, 2. Aufl., Bd. I, 2004, Art. 3 Rn. 100 ff; Englisch in: Stern/ Becker, Grundrechte-Kommentar, 2010, Art. 3 Rn. 96 ff.

41 BVerfGE 92, 91, 109; BVerfGE 109, 64, 89.

42 Deutlich formuliert in BVerfGE 89, 276, 285 f, wo $\$ 611$ a BGB aF als Ausdruck einer grundrechtlichen Schutzpflicht interpretiert wird. Normative Grundlage dafür ist Art. 3 Abs. 2 S. 1 GG; möglich wäre auch Art. 3 Abs. 3 S. 1 GG, was für die übrigen Merkmale von Relevanz wäre, dazu weiterführend Ruffert, Vorrang der Verfassung und Eigenständigkeit des Privatrechts, 2001, $178 \mathrm{ff}$. Ablehnend zum Konzept einer Schutzpflicht aus Art. 3 GG Isensee in: Isensee/Kirchhof, HbStR, 2. Aufl., Bd. V, 2000, \111 Rn. 96; Jestaedt, VVDStRL (64) 2005, 299, 343 ff; zum Streitstand näher Britz, VVDStRL (64) 2005, 355, 362 f; Dammann, Die Grenzen zulässiger Diskriminierung im allgemeinen Zivilrecht, $2005,77 \mathrm{ff}$.

43 BVerfGE 92, 91, 109; BVerfGE 109, 64, 89.

44 Vgl. BVerfGE 114, 357-71; dazu sehr kritisch di Fabio, AöR (122) 1997, 404, 406 ff.

45 Siehe BVerfGE 92, 91, 109; aus der Literatur speziell zum Thema von Frauenquoten Papier/Heidebach, ZGR 2011, 305, 314 f (,[E]ine Ungleichbehandlung anhand des in Art. 3 Abs. 3 GG aufgeführten Differenzierungskriteriums "Geschlecht" [lässt sich] nur durch kollidierendes Verfassungsrecht rechtfertigen, das zugleich den legitimen Zweck der Ungleichbehandlung darstellt. Als kollidierendes Verfassungsrecht kann nach der Rechtsprechung des Bundesverfassungsgerichts Art. 3 Abs. 2 Satz 2 GG herangezogen werden.“). Deutlich kritisch dagegen Sachs, ZG 2012 (Heft 1) unter I 2 a („Der insoweit gern genannte Art. 3 Abs. 2 Satz 2 GG kommt allerdings für eine Rechtfertigung von Unterscheidungen wegen des Geschlechts nicht in Frage.“).

46 Sacksofsky in: Umbach/Clemens, GG, Art. 3 II, III 1 Rn. 354; ähnlich auch Jarass in: Jarass/Pieroth, GG, Art. 3 Rn. 90: „bindender Auftrag an den Staat“.

47 Scharfe Kritik bei di Fabio, AöR (122) 1997, 404, 441 ff. 
nahmen, die zur Erhöhung des Frauenanteils in den Funktionssystemen der Gesellschaft beitragen. ${ }^{48}$ Es geht darum sicherzustellen, dass Frauen in der gesellschaftlichen Wirklichkeit dieselben Freiheitsmöglichkeiten haben wie Männer. ${ }^{49}$ Dabei hat der Gesetzgeber bei der Entscheidung darüber, wie er diesem Schutzauftrag nachkommt, im Ausgangspunkt einen erheblichen Gestaltungsspielraum. ${ }^{50}$ Die Palette an möglichen Handlungsoptionen ist groß. ${ }^{51}$ Ob Art. 3 Abs. 2 S. 2 GG allerdings auch die Herstellung „paritätischer“ Repräsentanz von Frauen und Männern in allen gesellschaftlichen Bereichen legitimiert, ist zweifelhaft. ${ }^{52}$ Darüber wird lebhaft gestritten..$^{53}$

\section{Diversity}

\section{a) Begriff}

Diversity (Vielfalt, Diversität) ist ein schillernder Begriff. ${ }^{54}$ Im Ausgangspunkt beschreibt es eine vielschichtige Zusammensetzung einer Gruppe. Diese Vielfalt kann auf unterschiedlichsten Merkmalen von Personen beruhen. ${ }^{55}$ Dazu zählen regelmäßig auch persönliche Eigenschaften und Zuschreibungen, an die anzuknüpfen das spezielle Nichtdiskriminierungsrecht grundsätzlich verbietet. Die Merkmale „Rasse“ und ethnische Herkunft, Geschlecht und Alter spielen in der globalen Praxis eine herausgehobene Rolle. Diversity knüpft also bewusst an klassische Diskriminierungsmerkmale an, um positive Gruppeneffekte zu erzeugen. Grundlage dafür sind wirtschaftspsychologische und ökonomische Untersuchungen über die Auswirkungen einer heterogenen Gruppenzusammensetzung auf das Gruppenverhalten: Nach Brewer und Kramer (1985) beeinflusst unsere Zugehörigkeit zu einer bestimmte Gruppe unsere Annahmen über gruppeneigenes und gruppenfremdes Verhalten, Intentionen und Werte. Das macht die antizipierende Einrichtung von „Wissensstrukturen “ in den jeweiligen Gruppen notwendig, um die Differenz des Anderen berücksichtigen zu können. Die innerhalb von Gruppen bestehenden Vorurteile können abgebaut werden, wenn es dort überlappende Kategorien (cross-cutting category distinctions) gibt. Multiple Grenzziehungen (multiple category boundaries) verhin-

48 Vgl. Osterloh in: Sachs, GG, 6. Aufl., 2011, Art. 3 Rn. 261; ähnlich wie hier auch Ossenbühl, NJW 2012, 417 („Für das hier in Rede stehende legislative Projekt einer Förderung der Repräsentanz von Frauen in den Leitungsgremien der Unternehmen kann der Gesetzgeber sich auf das verfassungsrechtliche Mandat des Art. 3 II 2 GG berufen. “)

49 Siehe BVerfGE 89, 276, $285 \mathrm{f}$.

50 BVerfGE 109, 64, 90.

51 Darauf weisen bereits Frost/Linnainmaa, AG 2007, 601, $609 \mathrm{f}$ unter Berücksichtigung der Handlungsoptionen nordischer Staaten hin.

52 So mit Nachdruck auch Osterloh, in: Sachs, GG (Fn. 48), Art. 3 Rn. 283.

53 Siehe dazu im Wesentlichen bejahend Papier/Heidebach,, ZGR 2011, 305, 314 ff; deutlich verneinend dagegen Sachs, ZG 2012 (Heft 1) unter II; differenzierend Ossenbühl, NJW 2012, 417, $418 \mathrm{f}$

54 Vgl. dazu Lembke, Rechtswissenschaft 2012, 47 (in diesem Heft). Zur Verwendung des Begriffs im DCGK Rieder/Holzmann, AG 2010, 570, 572.

55 Vgl. dazu näher Milliken/Martins, 21 Academy of Management Review 402, 403-04 (1996). 
dern einfache Insider-Outsider-Kategorisierungen und reduzieren das soziale Identifikations- und Abgrenzungspotential eines einzigen Merkmals. ${ }^{56}$ Die Beteiligung von Minderheiten in Gruppenprozessen ist nach Nemeth (1986) relevant für die Entscheidungsfindung in der Gruppe. ${ }^{57}$ Personen, die den Argumenten von Minderheitengruppen ausgesetzt waren, unternehmen dabei nämlich größere kognitive Anstrengungen. Das erlaubt eine größere Bandbreite von Ansichten, alternative und neue Lösungsansätze werden ernsthaft in Betracht gezogen und bestehende kritisch evaluiert. ${ }^{58}$

\section{b) Verwurzelung im U.S.-amerikanischen Gleichheitsdiskurs}

Im Recht ist das Konzept „Diversity“ ein legal transplant aus den U.S.A. Dort spielt es seit geraumer Zeit eine wichtige Rolle bei der Rechtfertigung von affirmative action-Programmen staatlicher ${ }^{59}$ Universitäten. In den späten 1960er Jahren begann man, „Rasse“ und ethnische Herkunft der Studienbewerber als relevante Kriterien bei der Aufnahmeentscheidung einzusetzen. ${ }^{60}$ Das ist angesichts des strikten einfach- ${ }^{61}$ und verfassungsrechtlichen ${ }^{62}$ Diskriminierungsverbots problematisch. ${ }^{63} \mathrm{Die}$ Universitäten argumentieren, damit einen „diverse student body “ zu schaffen. ${ }^{64}$ Der Supreme Court sieht darin im Grundsatz ein legitimes Ziel: Die Universität könne ihre wissenschaftliche Aufgabe nur erfüllen, wenn ihre Studierenden einer großen Bandbreite moralischer und ethischer Ansichten und Erfahrungen ausgesetzt seien. ${ }^{65}$ Eine vielfältig zusammengesetzte Studierendenschaft fördere „cross-racial understanding", trage dazu bei, stereotype Annahmen über ethnische Minderheiten abzubauen, ${ }^{66}$ und bereite den Einzelnen besser auf seine Mitwirkung in einer „in-

56 Brewer/Kramer, 36 Annual Review of Psychology 219 (1985).

57 Nemeth, 93 Psychological Review 23 (1986).

58 Nemeth, 93 Psychological Review 23, 25 (1986).

59 Zur state action-Doktrin grundlegend Civil Rights Cases, 109 U.S. 3, 11 (1883), in jüngerer Zeit U.S. v. Morrison, 529 U.S. 598 (2000). Näher dazu im deutschen Schrifttum Giegerich, Privatwirkung der Grundrechte in den USA, 1992, 185-214 und Heun, VVDStRL (61) 2002, 80, 90-93.

60 Siehe Regents of University of California v. Bakke, 438 U.S. 265 (1978).

61 Vgl. Civil Rights Act von 1866 [42 U.S.C. $\$ 1981$ und $\$ 1982$ ] und Title VII des Civil Rights Act von 1964 [42 U.S.C. \$2 2000 e et seq]; siehe Gratz v. Bollinger, 539 U.S. 244, 275 f (2003).

62 Grundlegend Korematsu v. U.S, 323 U.S. 214 (1944); Brown v. Board of Education, 347 U.S. 483 (1954) und in jüngerer Zeit Adarand Constructors, Inc. v. Pena, 515 U.S. 200, 224 (1995) [„,any person, of whatever race, has the right to demand that any governmental actor subject to the Constitution justify any racial classification subjecting that person to unequal treatment under the strictest judicial scrutiny"].

63 Zum Ganzen näher Chemerinsky, Constitutional Law, 3rd ed., 2007, 690 ff; aus dem deutschen Schrifttum Damm, Menschenwürde, Freiheit, komplexe Gleichheit: Dimensionen grundrechtlichen Gleichheitsschutzes, 2006, 214 ff. Instruktiv zum Modell unterschiedlicher Prüfungsdichte und seiner sozial-historischen Einbettung Balkin, 26 Card. L. Rev. 1689, $1712 \mathrm{ff}$ (2005).

64 Grundlegend Regents of University of California v. Bakke, 438 U.S. 265 (1978); Grutter v. Bollinger, 539 U.S. 306 (2003); Gratz v. Bollinger, 539 U.S. 244 (2003).

65 Regents of University of California v. Bakke, 438 U.S. at 311-15; Grutter v. Bollinger, 539 U.S. 306, 329 (2003).

66 Grutter v. Bollinger, 539 U.S. at 330. 
creasingly diverse workforce and society " vor. ${ }^{67}$ Das geht nicht ohne Berücksichtigung statistischer Zusammenhänge. ${ }^{68}$ Für die verfassungsrechtliche Zulässigkeit von Quoten kommt es im Ergebnis darauf an, wie strikt oder wie flexibel sie gehandhabt werden. ${ }^{69}$

Diversity ist im U.S.-amerikanischen Nichtdiskriminierungsrecht ein Rechtfertigungsgrund für formale Ungleichbehandlungen. Das teilt er mit den klassischen affirmative action-Programmen. ${ }^{70}$ Affirmative action basiert auf einer materiellen Konzeption ${ }^{71}$ der Diskriminierungsverbote: ${ }^{72} \mathrm{Um}$ die bestehenden diskriminierenden Strukturen zu bekämpfen, muss man zunächst die Differenz der Personen im Recht wieder sichtbar machen, um die ungleiche Behandlung erfolgreich bekämpfen zu können: „In order to get beyond racism, we must first take account of race. There is no other way. And in order to treat some persons equally, we must treat them differently. " ${ }^{73}$ Das ist die dialektische Lösung ${ }^{74}$ des Paradoxons der Gleichheit. ${ }^{75}$ Diese ist der konservativen Mehrheit am Supreme Court mittlerweile suspekt. Sie bevorzugt wieder die einfache Lösung über den formalen Gleichheitsbegriff. ${ }^{76}$ Ursache dafür ist der schwache Textbefund des U.S.-Rechts, das im Wesentlichen ${ }^{77}$ keinen ausdrücklichen Anhaltspunkt für eine materielle Konzeption des Gleichbehandlungsrechts enthält. Das setzt affirmative-action-Programme unter erheblichen Le-

67 Grutter v. Bollinger, 539 U.S. at 330.

68 Grutter v. Bollinger, 539 U.S. 336 unter Verweis auf Regents of University of California v. Bakke, 438 U.S. at 323.

69 Vgl. dazu Gratz v. Bollinger, 539 U.S. 244 (2003), wo das Gericht die standardisierte Berücksichtigung der ethnischen Herkunft in den Aufnahmekriterien des University of Michigan's College of Literature, Science and the Arts für verfassungswidrig erklärte, während es in Grutter v. Bollinger, 539 U.S. 306 (2003) die individualisierten Aufnahmefaktoren der Law School für einstweilen noch verfassungsgemäß hielt. Grundlegend Regents of University of California v. Bakke, 438 U.S. at 315, wo die Verfassungsmäßigkeit einer „starren Quote“ (16 von 100 Plätzen waren für Studierende reserviert, die als Angehörige einer Minderheit „benachteiligt“ waren) iE verneint wurde.

70 Sehr instruktiv zur Entwicklung und zur Unterscheidung von affirmative action und diversity managmement: Gilbert/Stead/Ivancevich, 21 J. of Business Ethics 61 (1999).

71 Zur Problemstellung Fredman, Discrimination Law, 2002, 122 ff.

72 Vgl. Adarand Constructors, Inc. v. Pena, 515 U.S. 200, 228 (1995) [, "strict scrutiny does take “relevant differences" into account-indeed, that is its fundamental purpose."].

73 Regents of University of California v. Bakke, 438 U.S. 265, 407 (1978)(Blackmun, J., conc. \& diss. in part).

74 Eingehend Menke, Spiegelungen der Gleichheit, 2004, $22 \mathrm{ff}$.

75 Dazu Alexy, Theorie der Grundrechte, 1994, $378 \mathrm{f}$.

76 Siehe Parents Involved In Community Schools v. Seattle School Dist. No. 1, 551 U.S. 701, 748 (2007) [,The way to stop discrimination on the basis of race is to stop discriminating on the basis of race"] zum verfassungsrechtlichen und Ricci v. DeStefano, 129 S.Ct. 2658 (2009) zum einfachrechtlichen Diskriminierungsverbot. Ganz deutlich - wenn auch damals noch in der Minderheit - Adarand Constructors, Inc. v. Pena, 515 U.S. 200, 239 (1995)(Scalia, J., conc.): „In my view, government can never have a "compelling interest" in discriminating on the basis of race in order to "make up" for past racial discrimination in the opposite direction."

77 Eine Ausnahme ist Verankerung des disparate treatment claim im Title VII des Civil Rights Act 1964 durch den Civil Rights Act 1991 [105 Stat. 1071]; vgl. dazu Ricci v. DeStefano, 129 S.Ct. at 2673. Diese wird von Vertretern einer strikt formalen Gleichheitskonzeption verfassungsrechtlich angegriffen, siehe Ricci v. DeStefano, 129 S.Ct. 2658 at 2682 (Scalia, J., conc.). 
gitimationsdruck. ${ }^{78}$ In dieser Hinsicht sind Unionsrecht und deutsches Verfassungsrecht freilich ganz anders gelagert: Die materielle Konzeption des Diskriminierungsverbots ist auf allen Stufen der Normhierarchie ausdrücklich verankert. ${ }^{79}$

Für Diversity ist die formale Ungleichbehandlung von Personen ebenfalls ein Mittel. Es dient aber dem freiheitsrechtlichen Schutz des ungleich Behandelnden, sein autonom gesetztes und schutzwürdiges Ziel mit einer Differenzierung besser erreichen zu können. Diversity sensibilisiert das Recht dafür, dass es die Eigenrationalität seiner Umwelt bei der Anwendung des Prinzips formaler Gleichheit berücksichtigt. Mit dem Diversity-Argument kann man die von einer strikt formalen Konzeption des Gleichbehandlungsrechts gerissene Bresche teilweise wieder schließen. Diversity adressiert das Problem struktureller Ungleichheiten in der Gesellschaft allerdings nicht unmittelbar gleichheitsrechtlich. Es basiert auf einem freiheitsrechtlichen Verständnis, das lediglich mittelbar zur Verbesserung materialer Gleichheit beitragen kann. Gleichstellungspolitik ist darin kein Zweck an sich, sondern wird zum Mittel, ökonomische Ziele zu erreichen.

\section{c) Business Case für Diversität?}

(1) Ein Zusammenhang zwischen Gender Diversity und dem Unternehmensinteresse?

Die Relevanz von Diversity in Entscheidungsgremien der Unternehmen ist in den letzten 20 Jahren intensiv untersucht worden. ${ }^{80}$ Dabei konzentriert man sich auf die Auswirkung der heterogenen Zusammensetzung des Board of Directors im monistischen U.S.-Modell. ${ }^{81}$ Mittlerweile gibt es eine Reihe von Studien im europäischen

78 Vgl. dazu Ricci v. DeStefano, 129 S.Ct. at 2675-76 und die überzeugende Kritik in Ricci v. DeStefano, 129 S.Ct. 2658, 2701 (2009)(Ginsburg, J., diss.).

79 Zu den Textgrundlagen Grünberger, Personale Gleichheit (Fn. 1), 743-57.

80 Grundlegend der Überblick von Milliken/Martins, 21 Academy of Management 402 (1996).

81 Vgl. dazu Dwyer/Richard/Chadwick, 56 J. of Business Research 1009 (2003); Erhardt/Werbel/Shrader, 11 Corporate Governance 102 (2003); Arfken/Bellar/Helms, 50 J. of Business Ethics 177 (2004); Farrell/Hersch, 11 J. of Corporate Finance 85 (2005); Brammer/Millington/Pavelin, 15 Corporate Governance 393 (2007); De Abreu Dos Reis/Sastre/Roig, 1 Service Business 257 (2007); Peterson/ Philpot, 72 J. of Business Ethics 177 (2007); Peterson/Philpot/O'Shaughnessy, 15 Corporate Governance: 558 (2007); Francoeur/Labelle/Sinclair-Desgagné, 81 J. of Business Ethics 83 (2008); Terjesen/Singh, 83 J. of Business Ethics 55 (2008); Adams/Ferreira, 94 J. of Financial Economics 291 (2009); Brammer/Millington/Pavelin, 20 British J. of Management 17 (2009); Miller/Del, 46 J. of Management Studies 755 (2009); Terjesen/Sealy/Singh, 17 Corporate Governance 320 (2009); Wang/ Clift, 21 Pacific Accounting Review 88 (2009); Bear/Rahman/Post, 97 J. of Business Ethics 207 (2010); Carter/D’Souza/Simkins/Simpson, 18 Corporate Governance 396 (2010); Rodríguez-Domínguez/ García-Sánchez/Gallego-Álvarez, European J. of Law and Economics 2010, 1, (2010); Shilton/McGregor/Tremaine, 25 Gender in Management 275 (2010); Ye/Zhang/Rezaee, 26 Advances in Accounting 47 (2010); Brady, 26 Gender in Management 104 (2011); Dobbin/Jung, 89 N.C.L. Rev. 809 (2011). 
Kontext. ${ }^{82}$ Gemeinsam ist den hier repräsentativ genannten Arbeiten die Fragestellung: „Is there a 'business case' for board diversity?" 83 Auf der Grundlage moderner Corporate Governance Theorien ${ }^{84}$ nimmt man an, dass sich die Präsenz von Frauen in Führungsgremien positiv auf das Unternehmensergebnis auswirkt oder in der Unternehmensbewertung niederschlägt. ${ }^{85}$ Dafür gibt es im Kern drei sich gegenseitig ergänzende Erklärungsansätze: ${ }^{86}$ (1.) Ein unter Gender Diversity-Aspekten zusammengesetztes Gremium beschäftigt sich intensiver mit alternativen Lösungen. Frauen können dazu aufgrund ihrer unterschiedlichen Erfahrung und Sozialisation einen wesentlichen Beitrag leisten. (2.) Gender Diversity ist ein Anwendungsfall von Corporate Social Responsibility (CSR). Darunter versteht man ein „Konzept, das den Unternehmen als Grundlage dient, auf freiwilliger Basis soziale Belange und Umweltbelange in ihre Unternehmenstätigkeit und in die Wechselbeziehungen mit den Stakeholdern zu integrieren. " ${ }^{87}$ Ein hoher CSR-Index beeinflusst die Reputation des Unternehmens am Markt und unter den Investoren und sorgt damit mittelbar für bessere Unternehmensergebnisse und einen steigenden Unternehmenswert. ${ }^{88}$ (3.) Der einseitige Blick auf Männer als potentielle Kandidaten für Entscheidungsgremien beschränkt den Wettbewerb. Öffnet man ihn auch für Frauen, kann es zu einer Qualitätssteigerung der Kandidaten insgesamt kommen. Wenn der Pool geeigneter Kandidaten insgesamt wächst, steigert das Unternehmen langfristig seine Produktivität. Nach gesicherter Erkenntnis treten diese positiven Effekte jedenfalls nur dann auf,

82 Siehe dazu Campbell/Minguez-Vera, 83 J. of Business Ethics 435 (2008); Campbell/Minguez, 14 J. of Management and Governance 37 (2010) (jeweils zu Spanien); Marinova/Plantenga/Remery, Gender Diversity and Firm Performance: Evidence from Dutch and Danish Boardrooms, Utrecht School of Economics Tjalling C. Koopmans Research Institute Discussion Paper Series 10-03 2010, http:// www.uu.nl/SiteCollectionDocuments/REBO/REBO_USE/REBO_USE_OZZ/10-03.pdf (zuletzt besucht: 24.1.2011), (zu den Niederlanden und Dänemark); Lückerath-Rovers, J. of Management and Governance (online) DOI 10.1007/s10997-011-9186-1 zu den Niederlanden; Smith/Smith/Verner, 55 I'ntl J. of Productivity and Performance Management 569 (2006); Rose, 15 Corporate Governance 404 (2007) (zu Dänemark) Huse/Nielsen/Hagen, 89 J. of Business Ethics 581 (2009); Elstad/Ladegard, $20 \mathrm{~J}$. of Management and Governance 1 (2010); Nielsen/Huse, 18 Corporate Governance 136 (2010); Nielsen/Huse, 7 European Management Review 16 (2010) jeweils (Norwegen); Grosvold/Brammer/ Rayton, 16 Business Ethics 344 (2007) (Norwegen und UK im Vergleich); Pesonen/Tienari/Vanhala, 24 Gender in Management 327 (2009); Virtanen, 14 J. of Management and Governance 1 (2010) (Finnland).

83 So der Titel des Beitrags von Wang/Clift, 21 Pacific Accounting Review 88 (2009).

84 Vgl. dazu Kim/Burns/Prescott, 17 Corporate Governance 728 (2009). Zu den unterschiedlichen Begründungsansätzen (agency und stakeholder theory) vertiefend Francoeur/Labelle/Sinclair-Desgagné, 81 J. of Business Ethics 83 (2008).

85 Vgl. dazu den ausführlichen Überblicksaufsatz Terjesen/Sealy/Singh, 17 Corporate Governance 320 (2009).

86 Vgl. dazu den Überblick bei Smith/Smith/Verner, 55 I'ntl J. of Productivity and Performance Management 569, $570 \mathrm{f}$ (2006).

87 Grünbuch Europäische Rahmenbedingungen für die soziale Verantwortung der Unternehmen, $\operatorname{KOM}(2001) 366$ endg. Rn. 20.

88 Dazu näher Bear/Rahman/Post, 97 J. of Business Ethics 207 2010). 
wenn im Entscheidungsgremium eine „kritische Masse“ von Frauen vorhanden ist. ${ }^{89}$ Eine rein symbolische Besetzung genügt nicht, weil damit die Homogenität der Gruppe nicht durchbrochen wird und das spezifische Potential des anderen Standpunkts sich nicht entfalten kann. ${ }^{90}$

Zwei Studien sorgten für die Breitenwirkung des Business Case: Catalyst publizierte 2004 eine Untersuchung, nach der 353 Fortune 500-Unternehmen mit dem höchsten Frauenanteil im Topmanagement eine durchschnittlich um 35,1 \% höhere Eigenkapitalrendite (return on equity) und eine um $34 \%$ höhere Aktienrendite (total return to shareholders) erzielten. ${ }^{91}$ Diesen Trend bestätigte eine von McKinsey erstmals im Jahr 2007 veröffentlichte und seitdem regelmäßig fortgeschriebene Studie. ${ }^{92}$ Danach bestehe eine Korrelation zwischen verbesserten Abläufen der Unternehmensorganisation und den Unternehmensergebnissen, wenn es mindestens drei Frauen im Vorstand (management committee) gebe. ${ }^{93}$ Beide Untersuchungen sind allerdings erheblichen methodischen Bedenken ausgesetzt. ${ }^{94}$ Dieses Defizit wird von einer ganzen Reihe jüngerer Studien ausglichen, die einen Zusammenhang zwischen Diversity und Unternehmensergebnis im Kern bestätigen konnten. ${ }^{95}$ Manche wollen sogar eine kausale Beziehung erkennen. ${ }^{96}$ Den damit verbundenen methodischen Einwänden können Untersuchungen entgehen, die sich auf indirekte Zusammenhänge beschränken. Danach führe Diversity u.a. zu einem „reputation-building effect“ und steigere

89 Kramer/Konrad/Erkut, Wellesley Centers for Women, Report No. WCW 11 2006; ähnlich Campbell/ Minguez-Vera, 83 J. of Business Ethics 435 (2008); Rodríguez-Dominguez/García-Sánchez/GallegoÁlvarez, European J. of Law and Economics 2010, 1, (2010); weitere Nachweise bei Terjesen/Sealy/ Singh, 17 Corporate Governance 320, 328 (2009). Siehe dazu auch die Ergebnisse einer norwegischen Studie, die diese Hypothese bestätigt, Elstad/Ladegard, 20 J. of Management and Governance 1 (2010).

90 Grundlegend zur Theorie des tokenism Kanter, Men and Women of the Corporation, 1977, $218 \mathrm{ff}$ und zur Gefahr, von der dominaten Mehrheit mit den klassischen Stereotypen konfrontiert zu werden (stereotype threat) Spencer/Steele/Quinn, 35 J. of Experimental Social Psychology 4 (2006) und Nielsen/Huse, 7 European Management Review 16 (2010).

91 Catalyst, The Bottom Line: Connecting Corporate Performance and Gender Diversity, 2004, http:// www.catalyst.org/publication/82/the-bottom-line-connecting-corporate-performance-and-gender-diversity (zuletzt besucht: 21.8.2011).

92 McKinsey \& Co., Women Matter, erhältlich unter http://www.mckinsey.de/html/publikationen/women_matter/index.asp, S. 12 [Stand: 21.8.2011].

93 McKinsey \& Co., Women Matter [Fn. 92]; S. $11 \mathrm{ff}$.

94 Dazu eingehend Lückerath-Rovers, J. of Management and Governance (online) DOI 10.1007/ s10997-011-9186-1.

95 Erhardt/Werbel/Shrader, 11 Corporate Governance 102 (2003); Smith/Smith/Verner, 55 I'ntl J. of Productivity and Performance Management 569 (2006); Campbell/Minguez-Vera, 83 J. of Business Ethics 435 (2008); Francoeur/Labelle/Sinclair-Desgagné, 81 J. of Business Ethics 83 (2008); Lückerath-Rovers, J. of Management and Governance (online) DOI 10.1007/s10997-011-9186-1; Rodríguez-Dominguez/García-Sánchez/Gallego-Álvarez, European J. of Law and Economics 2010, 1, (2010) (die auf die Bedeutung vergleichbarer Arbeitsbedingungen und Ausbildung hinweisen); weitere Nachweise bei Terjesen/Sealy/Singh, 17 Corporate Governance 320, 329-30 (2009).

96 Smith/Smith/Verner, 55 I'ntl J. of Productivity and Performance Management 569, 579-80 (2006); Campbell/Minguez-Vera, 83 J. of Business Ethics 435 (2008); zurückhaltend dagegen Catalyst, The Bottom Line: Connecting Corporate Performance and Gender Diversity (Fn. 91). 
die Innovationsfähigkeit eines Unternehmens. ${ }^{97}$ Noch schwieriger ist die empirische Überprüfung der These, dass eine relevante Anzahl von Frauen die Bewertung der CSR des Unternehmens beeinflussten und sich damit mittelbar positiv auf das Unternehmen auswirkten. ${ }^{98}$ Gemeinsam ist den hier genannten Studien, dass eine Erhöhung des Frauenanteils zugleich den Unternehmenswert verbessert. Sie können also im Ergebnis Regulierungsansätze rechtfertigen, mit denen der Frauenanteil erhöht werden soll. ${ }^{99}$

Diese Ergebnisse sind nicht unumstritten. ${ }^{100}$ Beispielhaft dafür sind die unterschiedlichen Resultate zu niederländischen Unternehmen. ${ }^{101}$ Das Phänomen lässt sich mit alternativen Ansätzen erklären: Die Präsenz von Frauen kann darauf zurückgeführt werden, dass Unternehmen aufgrund eigener Präferenzen oder - praktisch wichtiger - äußeren Drucks - den Anteil an Frauen erhöhen und sich die Frauen daher erfolgreichere Unternehmen aussuchen würden. ${ }^{102}$ Man kann das Phänomen auch mit dem stereotype threat erklären, der beim Fehlen einer „kritischen Masse“ zu einer antizipierten Assimilationsleistung und Übernahme männlicher Verhaltensmuster bei Frauen führt. ${ }^{103}$ Erhebliche Bedeutung kommt der Kritik von Adams \& Ferreira (2009) zu: Sie bemängeln, dass sich die Untersuchungen auf zu kurze Zeiträume bezögen und daher fehleranfällig seien. ${ }^{104}$ Gender Diversity in Boards könne einen signifikanten positiven Einfluss auf die Funktionsfähigkeit des Gremiums und auf die Corporate Governance insgesamt haben. Es bestehe aber kein zwingender kausaler Zusammenhang zum gesteigerten Unternehmensergebnis. ${ }^{105} \mathrm{Im}$ Ergebnis seien divers besetzte Boards strengere Kontrolleure. Eine verpflichtende Quote würde sich aber negativ auf bereits erfolgreich geführte Unternehmen auswirken. Dobbin \&

97 Miller/Del, 46 J. of Management Studies 755 (2009); Østergaard/Timmermans/Kristinsson, 40 Research Policy 509 (2011); nach Brammer/Millington/Pavelin, 20 British J. of Management 17 (2009) allerdings nur bei Endkunden nahen Segmenten.

98 Bear/Rahman/Post, 97 J. of Business Ethics 207 (2010).

99 Ausdrücklich etwa Campbell/Minguez, 14 J. of Management and Governance 37 (2010).

100 Eine Übersicht über die ältere Literatur bietet De Abreu Dos Reis/Sastre/Roig, 1 Service Business 261-63 (2007); jüngere Kritik etwa bei Wang/Clift, 21 Pacific Accounting Review 88 (2009); Yel Zhang/Rezaee, 26 Advances in Accounting, incorporating Advances in International Accounting 47 (2010) und der Überblick bei Dobbin/Jung, 89 N.C.L. Rev. 809, 817-20 (2011).

101 Einen Zusammenhang nachweisen kann Lückerath-Rovers, J. of Management and Governance (online) DOI 10.1007/s10997-011-9186-1; dagegen können Marinova/Plantenga/Remery, Gender Diversity and Firm Performance: Evidence from Dutch and Danish Boardrooms (Fn. 82) die Hypothese nicht bestätigen.

102 Farrell/Hersch, 11 J. of Corporate Finance 85 (2005); dagegen aber Smith/Smith/Verner, 55 I'ntl J. of Productivity and Performance Management 569 (2006); Campbell/Minguez-Vera, 83 J. of Business Ethics 435 (2008).

103 Rose, 15 Corporate Governance 404 (2007).

104 Adams/Ferreira, 94 J. of Financial Economics 291 (2009).

105 Adams/Ferreira, 94 J. of Financial Economics 291, 292 (2009). 
Jung bilanzieren daher ernüchternd: „The big picture seems to be that gender board diversity does not help firms, and may hurt them. "106

Zusammenfassend ist ein Business Case für Gender Diversity in unternehmerischen Entscheidungsgremien möglich, aber keinesfalls gesichert. Ein wesentlicher Grund dafür ist das statistische Problem, einen empirischen Zusammenhang zwischen einem isolierten Faktor der Board-Zusammensetzung und dem Unternehmensergebnis herzustellen. ${ }^{107}$ Das schwächt Regulierungsansätze, die sich mit den behaupteten positiven Auswirkungen der Beteiligung von Frauen in Aufsichtsrat und Vorstand legitimieren. Das Bild ist durchwachsen: (1.) Eine unmittelbare positive Auswirkung auf die Unternehmensergebnisse lässt sich nicht mit ausreichender Sicherheit nachweisen. (2.) Unklar ist, ob die verstärkte Besetzung mit Frauen - zumal wenn sie auf Faktoren außerhalb des Unternehmens zurückgeführt wird - am Markt positive oder negative Auswirkungen auf den Börsenwert hat. (3.) Erreichen Frauen in Aufsichtsund Entscheidungsgremien eine kritische Masse, kann man einen positiven Zusammenhang zur Arbeitsweise des Gremiums und - sektorspezifisch - zur Unternehmensreputation feststellen. Gender Diversity stärkt damit die Corporate Governance und hat positive Auswirkungen auf CSR-Bewertungen. Damit verlagert sich das Problem allerdings nur auf eine andere Ebene, weil man jetzt nachweisen muss, dass CSR-Aktivitäten sich positiv auf das Unternehmensergebnis auswirken. ${ }^{108}$

\section{(2) Diversity in der Genderfalle}

"Gender unter dem Dach Diversity “109 birgt die Gefahr der „Re-Aktivierung zweigeschlechtlicher Denk- und Handlungsmuster". ${ }^{110}$ Das ist dann der Fall, wenn der Business Case mit den vermeintlich „geschlechterspezifischen Sichtweisen“ verknüpft wird, die gerade Frauen - weil sie Frauen sind - in die Unternehmensführung einbringen. Ein Beispiel dafür ist die Studie von Huse u.a. (2009): ${ }^{111}$ Der - nachweisbare - Einfluss von Frauen auf die Boardtätigkeit hänge von den ihnen zugeteilten Aufgaben ab, was auf „women's enhanced sensitivity towards others and their consideration of the interests and perspectives of multiple parties " zurückzuführen sei. ${ }^{112}$ Damit tappt das Diversitätsargument in die „Genderfalle.“ Angeblich gesicherte Kenntnisse der Evolutionsbiologie und modernen Hirnforschung, wonach

106 Dobbin/Jung, 89 N.C.L. Rev. 809, 837 (2011).

107 Carter/D’Souza/Simkins/Simpson, 18 Corporate Governance 396, 411 (2010); Lückerath-Rovers, J. of Management and Governance (online) DOI 10.1007/s10997-011-9186-1.

108 Kritisch dazu beispielsweise Mülbert, AG 2009, $766 \mathrm{ff}$.

109 Krell, FS Heide Pfarr, 2010, 147, 148.

110 Wetterer, Strategien rhetorischer Modernisierung. Gender Mainstreaming, Managing Diversity und die Professionalisierung der Gender-Expertinnen 2002, 129, 129.

111 Huse/Nielsen/Hagen, 89 J. of Business Ethics 581 (2009).

112 Nielsen/Huse, 18 Corporate Governance 136, 143 (2010). 
Frauen anders denken als Männer, ${ }^{113}$ sind widerlegt. ${ }^{114}$ Wenig besser ergeht es dem psychologischen Erklärungsansatz: Frauen führten besser, seien teamfähig, kooperativ und sozial kompetent. Männer zeigten dagegen Entschlussfähigkeit, Durchsetzungskraft, Risikobereitschaft, zu hohe Risikobereitschaft, wie angesichts der jüngsten Finanzkrise angemerkt wird. ${ }^{115}$ Frauen würden sich nur zögerlich in Wettkampfsituationen begeben. ${ }^{116}$ Das wird in atemberaubender Manier als Ergebnis der Evolution erklärt und letztlich auf das männliche Testosteron und den Menstruationszyklus der Frau ${ }^{117}$ zurückgeführt. ${ }^{118}$ Damit verkennt man, dass Führungsverhalten, -erfolg und das Geschlecht soziale Konstrukte sind, die mit interessengeleiteten Wahrnehmungen, Zuschreibungen und Bewertungen verbunden sind. ${ }^{119}$ Der Untersuchungsgegenstand „fabriziert“ die Geschlechterunterscheidungen und verdeckt diesen Vorgang mit dem „Anschein des Natürlichen“. ${ }^{120}$ Gender Diversity ist daher so zu konzipieren, dass sie nicht an Stereotype und bestehende Geschlechterhierarchisierungen anknüpft und diese damit legitimiert. ${ }^{121}$ Frauen sind nicht deshalb ein Gewinn, weil sie Frauen sind, sondern weil sie aufgrund ihres Geschlechts in einer wesentlich nach Genderkriterien hierarchisierten sozialen Umwelt anderen Erfahrungen ausgesetzt sind. ${ }^{122}$ Auf diese Erfahrungen können sie in Entscheidungssituationen zurückgreifen und daher eine Perspektive einbringen, die zur „besseren“ Entscheidung der gesamten Gruppe beiträgt. ${ }^{123}$

113 Vgl. zu diesem Ansatz in Fachbüchern zu Gender-Marketing Krell, Gender Marketing: Ideologiekritische Diskursanalyse einer Kuppelproduktion, in: Diaz-Bone/Krell, Diskurs und Ökonomie, 2009, $203 \mathrm{ff}$.

114 Ausführlich dazu Schmitz, Sex, gender, and the brain - biological determinism versus socio-cultural constructivism, in: Klinge/Wiesemann, Sex and Gender in Biomedicine, 2010, $57 \mathrm{ff}$.

115 Ausführlich dazu der Überblick von Croson/Gneezy, 47 J. of Economic Literature 448, 449-454 (2009).

116 Croson/Gneezy, 47 J. of Economic Literature 448, 464-66 (2009).

117 Chen/Katuscak/Ozdenoren, Why Can't a Woman Bid More Like a Man?, http://yanchen.people.si.umich.edu/papers/chen_katuscak_ozdenoren_demog20090520.pdf; Wozniak/Harbaugh/Mayr, The Menstrual Cycle and Performance Feedback Alter Gender Differences in Competitive Choices, 2010, http://harbaugh.uoregon.edu/Papers/Menstruation_Wozniak_201010.pdf [Stand: 21.8.2011].

$118 \mathrm{Zu}$ den Begründungsansätzen näher Croson/Gneezy, 47 J. of Economic Literature 448, 466-67 (2009).

119 Eingehend Krell, „Vorteile eines neuen, weiblichen Führungsstils“: Ideologiekritik und Diskursanalyse in: Krell (Hrsg.), Chancengleichheit durch Personalpolitik, 2008, 324 ff.

120 Dazu grundlegend Butler, Das Unbehagen der Geschlechter, 1991.

121 Diesen Aspekt betont besonders die Analyse von Diversity vom Standpunkt der Queer-Theory, siehe dazu weiterführend Bendl/Fleischmann/Walenta, 23 Gender in Management 382 (2008).

122 Vgl. Milliken/Martins, 21 Academy of Management 402, 404 (1996).

123 Vgl. dazu Sotomayor, 13 Berkeley La Raza L.J. 87, 92 (2002). 


\section{Regulierungsansätze zur Erhöhung des Frauenanteils in Führungspositionen}

\section{Selbstregulierung}

Von Selbstregulierung spricht man, wenn der Staat sich zurückhält, weil er davon ausgeht, dass ein Steuerungsziel im gesellschaftlichen Prozess besser erfüllt wird. ${ }^{124}$ Klassischer Ort der „Selbst-Regulierung“ der Bedürfnisse privater Akteure ist der Markt. ${ }^{125}$ Für das Privatrecht ist Selbstregulierung daher der Normalfall und eng mit den Begriffen „Vertrag“ und „Privatautonomie“,126 „Eigentum“ und „Vereinigungsfreiheit“ verbunden. Damit weist das Recht die Handlungs- und Entscheidungskompetenz dem einzelnen privaten Akteur zu. Im liberalen Rechtsmodell ist es diese Beurteilungsfreiheit, die produktives Entscheiden unter Ungewissheitsbedingungen erst ermöglicht. ${ }^{127}$ In der „Privatrechtsgesellschaft“ ${ }^{128}$ ist ordnungsbildendes Wissen „an eine Praxis des Ausprobierens von Lösungsstrategien gebunden, über die sich Konventionen aufgrund der praktischen Bewährung [...] und wechselseitiger Beobachtung der Handelnden bilden. "129 Aufgabe des Rechts ist es, unter Berücksichtigung der formalen Gleichheit in der Ausübung der Freiheitsrechte die Eigenrationalität des Privaten zu sichern. ${ }^{130}$

\section{a) Präferenzautonomie des Verbandes}

Die Bestellung der Organmitglieder ist Bestandteil der Verbandsautonomie. ${ }^{131}$ Das Recht akzeptiert damit, dass der Verband diese Auswahlentscheidung an seinen eigenen Präferenzen orientiert. Dieser Freiheitsraum wird gegenüber staatlicher Regulierung geltend gemacht, wenn behauptet wird, die Einheitsquote verstoße gegen die von Art. 9 Abs. 1 GG geschützte Verbandsautonomie, ${ }^{132}$ gegen die Berufsfreiheit des Verbandes (Art. 12 Abs. 1 GG) ${ }^{133}$ und den Eigentumsschutz der Gesellschafter (Art. 14 Abs. 1 GG). ${ }^{134}$

124 Schulz/Held in: Hans-Bredow-Institut (Hrsg.), Regulierte Selbstregulierung als Form modernen Regierens, 2001, 7.

125 Schulz/Held in: Hans-Bredow-Institut (Hrsg.), Regulierte Selbstregulierung als Form modernen Regierens, 2001, 7; Buck-Heeb/Dieckmann, Selbstregulierung im Privatrecht, 2010, 33 ff, anders z. Bsp. Bachmann, Private Ordnung, 2006, 27.

126 Buck-Heeb/Dieckmann, Selbstregulierung im Privatrecht, 2010, 26.

127 Dazu Ladeur, Negative Freiheitsrechte und gesellschaftliche Selbstorganisation, 2000.

128 Zum Begriff grundlegend Böhm, ORDO (17) 1966, 75 ff; dazu und zu den modernen Konzeptionen vertiefend Grünberger, Personale Gleichheit (Fn. 1), 188 ff.

129 Ladeur, Der Staat gegen die Gesellschaft, 2006, 40.

130 Ladeur, Staat gegen Gesellschaft, 2006, $76 \mathrm{f}$.

131 Vgl. BVerfGE 50, 290, 353 ff; siehe dazu auch Papier/Heidebach, ZGR 2011, 305, $327 \mathrm{f.}$

132 Dazu grundlegend BVerfGE 50, 290, 353 ff; BVerfGE 99, 367 (jeweils zur Mitbestimmung); vgl. auch François-Poncet/Deilmann/Otte, NZG 2011, 450, 454.

133 Dazu Spindler/Brandt, NZG 2011, $401 \mathrm{ff}$.

134 Dazu Wieland, NJW 2010, 2408, 2409 f; Bachmann, ZIP 2011, 1131, 1134 und ausführlich Papier/ Heidebach, ZGR 2011, 305, $323 \mathrm{ff}$ (Verfassungswidrigkeit im Kern verneinend); bejahend dagegen Mülbert, ZHR (174) 2010, 375, 382; Redenius-Hövermann, ZIP 2010, 660, 665. 
Innerhalb des Verbandes trägt der Aufsichtsrat die „Vorschlagsverantwortung “, 135 \$ 124 Abs. 3 S. 1 AktG. Das Gesetz schränkt die Präferenzautonomie des Verbandes nur im Interesse guter Unternehmensführung ein. Der Aufsichtsrat hat sich bei seinem Wahlvorschlag an den gesetzlichen Aufgaben eines Aufsichtsratsmitglieds zu orientieren. Die Kandidaten müssen die Mindestkenntnisse und -fähigkeiten besitzen oder sich aneignen, die es braucht, um alle normalerweise anfallenden Geschäftsvorgänge auch ohne fremde Hilfe verstehen und sachgerecht beurteilen zu können. ${ }^{136}$ Nicht jedes einzelne Aufsichtsratsmitglied muss alle für die Arbeit des Aufsichtsrats erforderlichen Fachkompetenzen mitbringen. Die erforderlichen Fachkompetenzen müssen aber im Gesamtorgan ausreichend vorhanden sein. ${ }^{137}$ Das gilt insbesondere für den unabhängigen „Finanzexperten“, $\mathbb{} 100 \mathrm{Abs.} 5 \mathrm{AktG} .{ }^{138}$ Wegen der Personalkompetenz und der Zustimmungsvorbehalte muss das Aufsichtsratsmitglied mit den wesentlichen Geschäftsabläufen und der unternehmerischen Strategie vertraut sein. ${ }^{139}$ Eigene unternehmerische Erfahrung ist dagegen nicht erforderlich. ${ }^{140}$

\section{b) Ein Problem tatsächlicher Gleichheit}

Der Aufsichtsrat muss der Hauptversammlung die Kandidaten zur Wahl vorschlagen, die er - unabhängig von ihrem Geschlecht - für am Besten geeignet hält, dem Interesse der Gesellschaft und dem Gebot einer möglichst effektiven Überwachung durch das Aufsichtsorgan zu entsprechen. ${ }^{141}$ In der Praxis fällt diese Wahl ganz überwiegend auf Männer. ${ }^{142}$ Diese werden von dem ganz überwiegend aus Männern zusammengesetzten Aufsichtsrat als die geeigneten Kandidaten angesehen. Das hängt auch damit zusammen, dass man den Kandidatenpool vielfach immer noch auf Personen im Top-Management konzentriert, das ebenfalls fast ausschließlich mit Männern besetzt ist. ${ }^{143}$ Über die politischen, sozialen, wirtschaftlichen und psychologischen Ursachen dieser tatsächlichen Ungleichbehandlung wird ausgiebig diskutiert. ${ }^{144}$ Wie jede Ungleichbehandlung lassen sie sich im Ergebnis mit den Modellen der präferenzbedingten und der statistischen Diskriminierung erklären. ${ }^{145}$ Eine prä-

135 Habersack in: MünchKomm-AktG, 3. Aufl. 2008, \$101 Rn. 17.

136 BGHZ 85, 293, $295 \mathrm{f}$.

137 Kremer in: Ringleb/Kremer/Lutter/Werder, DCGK, 4. Aufl., 2010, Rn. 1015.

138 Wind/Klie, DStR 2010, 1339.

139 Habersack in: MünchKomm-AktG (Fn. 135), $\$ 116$ Rn. 25.

140 Hopt/Roth in: Großkommentar AktG, 4. Aufl. 2006, $\$ 116$ Rn. 44; Habersack in: MünchKommAktG (Fn. 135), $\$ 116$ Rn. 25.

141 Redenius-Hövermann, ZIP 2010, 660, 662.

142 S.o. II.

143 Redenius-Hövermann, ZIP 2010, 660, 662.

144 Vgl. die Darstellung im NRW-Entwurf (Fn. 16), S. 13 ff; Rudolph, Frauen in Aufsichtsräten, Frankfurt School of Finance and Management 2009, http://www.frankfurt-school.de/content/de/frauen_in_aufsichtsraeten/dmsFS/0/file1/Frauen-in-Aufsichtsraeten.pdf (zuletzt besucht: 21.8.2011), 8 ff.

145 Zum Folgenden eingehend Grünberger, Personale Gleichheit (Fn. 1), $591 \mathrm{ff}$. 
ferenzbedingte Diskriminierung liegt vor, wenn der Benachteiligende mit Angehörigen der Gruppe „Frau“ aus systemfremden Gründen nichts zu tun haben will. ${ }^{146}$ Die Präferenzen können auf stereotypen Rollenverständnissen der Geschlechter beruhen. ${ }^{147}$ Im Modell statistischer Diskriminierung geht man im Regelfall ${ }^{148}$ davon aus, dass es im System rationale Gründe für die Unterscheidung gibt. ${ }^{149}$ Die Differenzierung erfolgt anhand eines Stellvertretermerkmals, weil dieses in einer statistisch signifikanten Relation zum eigentlich entscheidungsrelevanten Hauptmerkmal steht, an das aus unterschiedlichen Gründen nicht unmittelbar angeknüpft werden kann. ${ }^{150}$ Die Entscheidung, Frauen nicht einzustellen oder nicht in Führungspositionen zu befördern, kann auf der Einschätzung beruhen, dass eine Frau (Stellvertretermerkmal) wegen einer zukünftigen Schwanger- oder Mutterschaft ausfallen und dadurch erhöhte Kosten (Hauptmerkmal 1) verursachen wird und keine kontinuierliche Berufsbiographie ${ }^{151}$ (Hauptmerkmal 2) vorlegen kann. Ein anderes Beispiel ist die verbreitete Annahme, dass Frauen aufgrund der unterstellten Doppelbelastung mit Beruf und Familie beruflich nur eingeschränkt leistungsfähig sind. Diese systeminterne Rationalität irritiert seine Umwelt als gravierendes Gerechtigkeitsproblem: Eine Frau wird - weil sie „Frau“ ist - ohne weiteres als ein Mitglied der Gruppe „Frauen“ behandelt, obwohl sie die damit zu erfassende Haupteigenschaft nicht notwendig aufweist. Die rationale Beziehung wird zum Stereotyp. ${ }^{152}$ Das Wirtschaftssystem (re-)produziert dadurch Ungleichheit von Männern und Frauen. Die Geschlechter haben im Ergebnis ungleiche Freiheitsräume: größere für Männer, kleinere für Frauen. Für das Recht stellt sich die Frage, wie es auf die damit einhergehende Irritation reagiert. Ausgangspunkt ist das Prinzip formal-abstrakter Gleichheit. Danach operiert das Recht „ohne Ansehung“ der Person. Die Umwelt des Rechts, insbesondere die Wirtschaft, differenziert aber offensichtlich „in Ansehung der Person“. Mit dem Institut der Verbandsautonomie kommt es zur strukturellen

146 Grundlegend Becker, The Economics of Discrimination (1957), 2nd ed., 1971.

147 Eindrucksvolle Beispiele aus dem deutschen Top-Management bei Wipperman, Frauen in Führungspositionen - Barrieren und Brücken, 2010 http://www.bmfsfj.de/BMFSFJ/Service/Publikationen/publikationen,did=134254.html (zuletzt besucht am 21.8.2011), $45 \mathrm{ff}$.

148 Es gibt auch Formen präferenzbedingter statistischer Diskriminierung, dazu Grünberger, Personale Gleichheit (Fn. 1), 596 ff, $600 \mathrm{ff}$.

149 Vgl. dazu allgemein Posner, 136 U. Pa. L. Rev. 513, 515-16 (1987); Wagner, Materialisierung des Schuldrechts unter dem Einfluss von Verfassungsrecht und Europarecht - Was bleibt von der Privatautonomie?, in: Blaurock/Hager (Hrsg.), Obligationenrecht im 21. Jahrhundert, 2010, 13, $55 \mathrm{f.}$

150 Grundlegend Arrow, Models of Job Discrimination, in: Pascal (Hrsg.), Racial Discrimination in Economic Life, 1972, 83; Phelps, 62 Am. Econ. Rev. 659 (1972); Arrow, The Theory of Discrimination, in: Ashenfelter/Rees (Hrsg.), Discrimination in Labor Markets, 1973, 3; ein aktueller Überblick bei Schwab, Employment Discriminiation, in: Dau-Schmidt/Harris/Lobel (Hrsg.), Labor and Employment Law and Economics, 2nd ed. 2009, 296, $303 \mathrm{ff}$ und aus der deutschen rechtswissenschaftlichen Literatur grundlegend Britz, Einzelfallgerechtigkeit versus Generalisierung, 2008.

151 Unterstrichen von Wipperman, Frauen in Führungspositionen - Barrieren und Brücken (Fn. 147), 69 ff; zurückhaltender die Einschätzung bei Rudolph, Frauen in Aufsichtsräten (Fn. 144), 34 f.

152 Eingehend Britz, Einzelfallgerechtigkeit vs. Generalisierung, 2008, $120 \mathrm{ff}$. 
Kopplung zwischen der präferenzgeprägten Entscheidung im Wirtschaftssystem und ihrer rechtlichen Stabilisierung. Damit gerät die Aufgabe des Rechts in Gefahr, die gleichen subjektiven Handlungsfreiheiten für alle durchzusetzen. ${ }^{153}$

\section{c) Freiwillige Selbstverpflichtung}

Die Steigerung des Frauenanteils in Führungspositionen kann theoretisch mit dem Instrument der freiwilligen Selbstverpflichtung erzielt werden. Praktisch hatte die kollektive Selbstverpflichtung aus dem Jahre $2001^{154}$ keine Auswirkungen auf das Geschlechterverhältnis in Vorstand und Aufsichtsrat. ${ }^{155}$ Ein Blick auf die Entwicklung der Geschlechterverteilung in Vorständen (Abbildung 1) und Aufsichtsräten (Abbildung 2) der CDAX-Unternehmen seit 1998 verdeutlicht das: ${ }^{156}$

Abbildung 1: Geschlechtsverteilung in Vorständen der CDAX-Unternehmen

$$
\text { - Männer - Frauen }
$$

100

$\begin{array}{lllllllllll}98,8 & 98,8 & 98,2 & 97,9 & 98 & 97,7 & 97,9 & 97,5 & 97,6 & 97,5 & 97,6\end{array}$

50

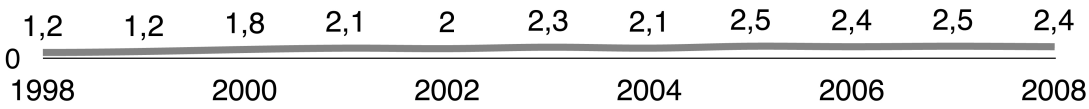

153 Vom Standpunkt des Materialisierungsparadigmas Habermas, Faktizität und Geltung, 1994, 483 f; vom Standpunkt einer gleichheitsrechtlich konzipierten Theorie juristischer Gerechtigkeit Grünberger, Personale Gleichheit (Fn. 1), 65 ff, $973 \mathrm{ff}$.

154 S.o. I.

155 Allg. Auffassung, vgl. Bachmann, ZIP 2011, 1131, 1133; Spindler/Brandt, NZG 2011, 401, 404; etwas verbrämt dagegen die 4. Bilanz Chancengleichheit der Bundesregierung und der Wirtschaftsverbände, zugreifbar unter http://www.bmfsfj.de/BMFSFJ/Service/Publikationen/publikationsliste, did=173736.html, S. 55 .

156 Siehe dazu die Studie des Karlsruher Instituts für Unternehmensführung, Insitut für Unternehmensführung, Frauen in Führungspositionen - Status Quo in der deutschen Wirtschaft (Fn. 20). 
Abbildung 2: Geschlechtsverteilung in Aufsichtsräten der CDAX-Unternehmen

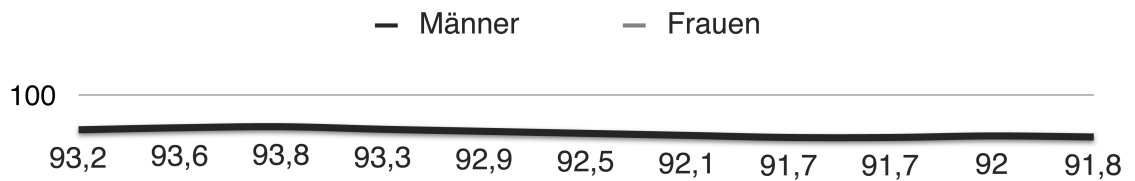

50

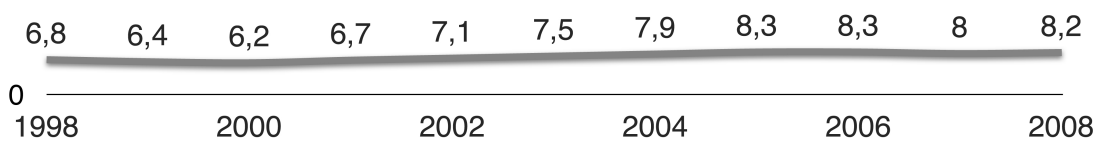

Erst in den letzten zwei Jahren lässt sich eine signifikante Steigerung feststellen. „Diese Entwicklungen sind wohl nicht zuletzt auf die Empfehlungen des Deutschen Corporate Governance Kodex sowie die politische Diskussion über gesetzliche Regelungen zurückzuführen. “157

Die kollektive Selbstverpflichtung scheiterte, weil die Funktionsvoraussetzungen erfolgreicher Selbstregulierung ${ }^{158}$ fehlten. Eine Selbstregulierung ist nur effektiv, wenn sich der einzelne Akteur im Wirtschaftssystem mit einer Anerkennungserklärung dem selbstregulativen Akt „unterwirft“ ${ }^{159}$ Das war nicht der Fall. Die Verpflichtung wurde von den Verbänden abgegeben, eigentlicher Regelungsadressat war aber das einzelne Unternehmen. Das Unternehmen muss den Impuls aus seiner Umwelt aufnehmen und systemintern durchsetzen können. Selbstregulierung kann nur dann gelingen, wenn sich das Unternehmen selbst einen entsprechenden Verhaltenscode setzt. Dieser wird innerhalb des Teilsystems „Unternehmen“ zum Bestandteil einer entsprechenden „Unternehmensverfassung“. Die Regeln dieses Verhaltenscodes sind Meta-Regeln, die innerhalb des Kommunikationsnetzwerks „Verband“ dem Rechts-

157 4. Bilanz Chancengleichheit (Fn. 155), S. 55.

158 Allgemein zu den Vor- und Nachteilen privater Selbstregulierung Bachmann, Private Ordnung, 2006, 55 ff; Buck-Heeb/Dieckmann, Selbstregulierung im Privatrecht, 2010, 220 ff, $229 \mathrm{ff}$.

159 Vgl. Buck-Heeb/Dieckmann, Selbstregulierung im Privatrecht, 2010, 229 f. 
code und dem Wirtschaftscode vorgehen. ${ }^{160}$ Eine freiwillige Selbstverpflichtung zur Steigerung des Frauenanteils in Führungspositionen kann also nur funktionieren, wenn sie unternehmensintern in einem "Code of Conduct" umgesetzt wird, der die Produktion verbandsinterner Operationen steuert. Dieser Code erlaubt nur die Bildung von Rechtsregeln, die mit den darin festgelegten vorrangigen Prinzipien zur Steigerung des Frauenanteils konform gehen. Er führt zur effektiven Selbstbeschränkung bei der Ausübung der vom staatlichen Recht erlaubten Präferenzautonomie. In ökonomischer Hinsicht verdrängt der Code den Primat des shareholder value und reflektiert die Verantwortung des Unternehmens für andere Teilsysteme der Gesellschaft.

Das ist erklärungsbedürftig: (1.) Warum sollte sich das Unternehmen „freiwillig“ diese Beschränkung seiner Kommunikationen auferlegen? „Freiwillig“ ist der Vorgang nur, wenn man Freiwilligkeit als Abwesenheit staatlichen Zwangs durch Recht definiert. Unternehmen gehen solche Selbstverpflichtungen „weder aus Einsicht in die Gemeinwohlanforderung noch aus Motiven der Unternehmensethik ein. 'Freiwillig' fügen sie sich nur wenn von außen massive Lern-Pressionen ausgeübt werden. " ${ }^{161}$ Nicht rechtliche Sanktionen, sondern außerrechtliche Mechanismen nötigen sie dazu. ${ }^{162}$ (2.) Wie können die Topoi „Steigerung des Frauenanteils“ und „Geschlechtergerechtigkeit“ überhaupt in das Unternehmen als prinzipiell geschlossenes Subsystem der Wirtschaft „übersetzt“ werden? Das gelingt, wenn man innerhalb des Wirtschaftssystems einen systemspezifischen Begriff findet, der eine strukturelle Kopplung mit seiner Umwelt ermöglicht. Ein solcher Begriff erlaubt es dem Wirtschaftssystem, die Forderung zur Steigerung des Frauenanteils aus dem politischen System und nach Geschlechtergerechtigkeit aus dem Rechtsystem als Bedingung seiner eigenen Organisation aufzubauen und zu benutzen. Dieser Begriff ist Diversity.

\section{d) Rechtfertigungsbedarf der Selbstregulierung}

Selbstregulierungen der Wirtschaft zur Förderung des Frauenanteils irritieren das Recht noch auf andere Weise. Sie kommen in Konflikt mit dem formalen Diskriminierungsverbot wegen des Geschlechts nach $\mathbb{\$} 7$ Abs. 1 iVm $\mathbb{S} 3$ Abs. 1 und $\mathbb{\$} 1$ AGG. ${ }^{163}$ Das wird bei der Diskussion über die Vorzüge der Selbstregulierung im Vergleich zur staatlichen Regulierung häufig übersehen. ${ }^{164}$ Das AGG dient u.a. der Umsetzung der Richtlinie 2006/54/EG zur Verwirklichung des Grundsatzes der

160 Eingehend dazu Teubner, Selbst-Konstitutionalisierung transnationaler Unternehmen?, FS Hopt, 2010, 1449, $1458 \mathrm{f}$.

161 Teubner, FS Hopt, 2010, 1449, 1468.

162 Vgl. auch Abbott/Snidal, 42 Vand.J. Transnat'l L. 501, 506 n. 26 (2009); unzureichend daher die Kritik von Bachmann, ZIP 2011, 1131, 1133.

163 Zur verfassungsrechtlichen Dimension selbstgesetzter Quotenregelungen Sachs, ZG 2012 (Heft 1) unter II 1.

164 Zutreffend die Diagnose bei Redenius-Hövermann, ZIP 2010, 660, 663. 
Chancengleichheit und Gleichbehandlung von Männern und Frauen in Arbeits- und Beschäftigungsfragen. ${ }^{165}$ Der gesamte Auswahl-, Entscheidungs- und Bestellungsprozess $^{166}$ zum Aufsichtsrat ist ein Vorgang, der bei einer vergüteten Tätigkeit in den sachlichen ( $\$ 2$ Abs. 1 Nr. 1 AGG) und persönlichen ( $\$ 6$ Abs. 3 AGG) Anwendungsbereich der Richtlinie und des AGG fällt. ${ }^{167}$ Kündigt das Unternehmen eine Selbstverpflichtung an, mit der es sich eine Frauenquote als Zielvorgabe setzt, liegt bereits darin ein objektiver Verstoß gegen das formale Diskriminierungsverbot. ${ }^{168}$ Solche Maßnahmen sind nur unter den Voraussetzungen des $\$ 5$ AGG bzw. Art. 3 der Richtlinie 2006/54/EG gerechtfertigt. ${ }^{169}$ Das Recht nimmt seinen Regulierungsanspruch unter zwei Bedingungen zurück: Die bevorzugte Berücksichtigung von Frauen muss (1.) einen bestehenden Nachteil wegen des Geschlechts verhindern oder ausgleichen und (2.) dafür geeignet und angemessen, also verhältnismäßig, sein, $\mathbb{} 5$ AGG. ${ }^{170}$

\section{Staatliche Regulierung}

Der Vorschlag, weiter auf die Selbstregulierung der Wirtschaft zu setzen, zieht den Einwand auf sich, „auf Freiwilligkeit und die Zeit [zu setzen], die es schon irgendwann richten werden ". ${ }^{171}$ Alternativ dazu bietet sich eine rechtliche Steuerung des Prozesses der Gleichstellung an. Eine vom Staat den Unternehmen für die Besetzung ihrer Organe vorgegebene Frauen- oder Geschlechterquote („Einheitsquote“)

165 ABl. L Nr. 204 v. 26.7.2006, S. 23.

166 Vgl. dazu EuGH Urt. v. 11.11.2010, Rs. C-232/09 - Danosa./. LKB Lizings SIA, Slg. 2010, I-(n.v.), wo der EuGH die im nationalen Recht angelegte Differenzierung $\mathrm{mE}$ bewusst nicht aufgreift, weil sie vom Standpunkt des Gleichbehandlungsrechts irrelevant ist, näher Grünberger, Personale Gleichheit (Fn. 1), 579 ff; aA Bauer/Göpfer/Krieger, Allgemeines Gleichbehandlungsgesetz - Kommentar, 3. Aufl., 2011, $\$ 6$ Rn. 27.

167 Dazu näher Eßer/Baluch, NZG 2007, 321 ff; Lutter, BB 2007, 725, 730; Schmidt in: Schiek, AGG, 2007, \$ 6 Rn. 14; Redenius-Hövermann, ZIP 2010, 660, 663 f; zurückhaltender Bauer/Göpfer/Krieger, AGG (Fn. 166), $\$ 6$ Rn. 28; aA Schladebach/Stefanopoulou, BB 2010, 1042, 1045 f.

168 Siehe EuGH Urt. v. 10.7.2008, C-54/07 - Centrum voor gelijkheid van kansen en voor racismebestrijding v. Firma Feryn NV, Slg. 2008, I-5187, Rn. 24; vertiefend Grünberger, Personale Gleichheit (Fn. 1), $578 \mathrm{f}$.

169 Zur Konzeption der positiven Maßnahme als Rechtfertigungsgrund vgl. EuGH Urt. v. 30.9.2010, Rs. 104/09 - Roca Álvarez v. Sesa Start España ETT SA, Slg. 2010, I-(n.v.), Rn. 25 f und aus der Literatur zum Unionsrecht Krebber in: Callies/Ruffert, EUV/EGV, 3. Aufl., 2007, Art. 141 Rn. 81; Rebhahn in: Schwarze, EU-Kommentar, 2. Aufl., 2009, Art. 141 Rn. 47, 49; wohl auch Epiney/Abt, Das Recht der Gleichstellung von Mann und Frau in der EU, 2003, 199. Zur Rechtfertigung einer (staatlich vorgegebenen) Quotenregelung mit dem Unionsrecht siehe auch Papier/Heidebach, ZGR 2011, 305, $330 \mathrm{ff}$.

170 Zum Quotenproblem s.u. IV.2.c).

171 Hohmann-Dennhardt, Berufliche Gleichstellung von Frauen - Notwendigkeiten und Formen einer Regulierung, FS Pfarr, 2010, 235, 239. 
kommt daher als effektive rechtliche Regelung zur beschleunigten beruflichen Gleichstellung von Frauen durchaus in Betracht. ${ }^{172}$

\section{a) Europäische Regelungsvorbilder}

Dafür gibt es eine Reihe unterschiedlich ausgestalteter Vorbilder im europäischen Ausland. Norwegen führte als erstes Land zwischen den Jahren 2004 und 2008 in drei Stufen eine verbindliche Geschlechterquote für die monistisch strukturierten Aktiengesellschaften (allmennaksjeselskap) ein: ${ }^{173}$ Besteht ein Board of Directors aus mehr als 9 Mitgliedern, muss jedes Geschlecht mit einer Quote von mindestens $40 \%$ vertreten sein. Bei Boards deren Mitgliederzahl zwischen 2 und 9 Personen beträgt, variiert die Quote je nach Mitgliederanzahl zwischen 1/3 und 1/2 (Mindestanteilsquote). ${ }^{174}$ Kommt die Gesellschaft diesen Anforderungen nicht nach, verletzt sie eine zwingende gesetzliche Regelung. Das führt nach allgemeinen Regeln zur Auflösung der Gesellschaft. Dem König bleibt bei allen Gesetzesverstößen die Möglichkeit, die Unternehmensauflösung aufgrund sozialer Erwägungen zu verhindern. ${ }^{175}$ In Spanien wurde im Jahr 2007 die Ley de igualdad verabschiedet, wonach alle Gesellschaften, die eine vollständige Gewinn- und Verlustrechnung vorlegen müssen, bis 2015 sicherzustellen haben, dass der Verwaltungsrat mit ausreichend Frauen besetzt ist, damit ein ausgewogenes Geschlechterverhältnis besteht. ${ }^{176}$ Das ist der Fall, wenn die Personen eines Geschlechts mit nicht mehr als $60 \%$ und die Personen des anderen Geschlechts mit nicht weniger als $40 \%$ vertreten sind. ${ }^{177}$ Erreicht das Unternehmen dieses Ziel nicht, läuft es lediglich Gefahr, dass es bei der Ausschreibung öffentlicher Aufträge leer ausgeht. ${ }^{178}$ Schärfer formuliert ist das im Januar 2011 verabschiedete französische Gesetz. ${ }^{179}$ Danach darf u.a. in börsennotierten Gesellschaften der Anteil jedes Geschlechts ab dem Jahr 2014 nicht unter

172 Siehe „Neue Wege - Gleiche Chancen. Gleichstellung von Frauen und Männern im Lebensverlauf“, Erster Gleichstellungsbericht: Gutachten der Sachverständigenkommission, Juni 2011, http:// www.bmfsfj.de/BMFSFJ/gleichstellung,did=172978.html, S. 207: „Zur Herstellung einer geschlechtergerechteren Besetzung in Leitungs- und Entscheidungspositionen spricht sich die Kommission dafür aus, eine Geschlechterquote für Aufsichtsräte einzuführen. Mit Blick auf die stagnierende Entwicklung der Frauen im Top-Management in Deutschland sollte eine Mindestanzahl weiblicher Mitglieder des Aufsichtsrats festgesetzt werden.“.

173 Weiterführend Storvik/Teigen, Das norwegische Experiment - eine Frauenquote für Aufsichtsräte, http://library.fes.de/pdf-files/id/ipa/07310.pdf (zuletzt besucht: 24.1.2011); Frost/Linnainmaa, AG 2007, 601, 603 ff; Raasch, ZfRV 2009, 216, 218 ff.

174 Siehe die deutsche Übersetzung der Regelung abgedruckt bei Frost/Linnainmaa, AG 2007, 601, 604.

175 Siehe näher Frost/Linnainmaa, AG 2007, 601, $604 \mathrm{f}$.

176 Art. 75 Ley organica 3/2007 v. 22.3.2007, para la igualdad efectiva de mujeres y hombres, BOE no. 71 v. 23.3.2007, S. 12611, erhältlich unter http://www.boe.es/.

177 Art. 78 (2) Ley de igualdad (Fn. 176).

178 Vgl. Art. 50 Ley de igualdad (Fn. 176).

179 Siehe Loi no. 2011-103 v. 27.1.2011 relative à la représentation équilibrée des femmes et des hommes au sein des conseils d' administration et de surveillance et à l' égalité professionnelle, JO no. 23 v. 28.1.2011, S. 2, erhältlich unter http://www.legifrance.gouv.fr/; dazu François-Poncet/Deilmann/Otte, NZG 2011, $450 \mathrm{ff}$. 
$20 \%$ und ab dem Jahr 2017 nicht unter 40 \% liegen. ${ }^{180}$ Jede Wahl bzw. Ernennung die dagegen verstößt, ist nichtig, wobei die gefassten Beschlüsse wirksam bleiben. ${ }^{181}$ Dazu kommt, dass die Vergütung der Mitglieder des gesetzeswidrig zusammengesetzten Organs suspendiert wird. ${ }^{182}$ Zurückhaltender ist das im Juli 2011 in Italien verabschiedete Gesetz. ${ }^{183}$ Das „Gleichgewicht zwischen den Geschlechtern in den Organen börsennotierter Gesellschaften “ soll in zwei Stufen erreicht werden: In der ersten, auf das Inkrafttreten folgenden Wahlperiode, müssen mindestens $20 \%$ der Sitze des Verwaltungsrat (consiglio di amministrazione) mit Mitgliedern des unterrepräsentierten Geschlechts besetzt werden. Diese Quote soll in den darauf folgenden Wahlperioden auf mindestens 1/3 der Verwaltungsratssitze steigen. Werden diese Ziele nicht erreicht, kann die Börsenaufsichtsbehörde Consob eine Geldbuße i.H.v. 100.000 bis 1 Million € verhängen.

\section{b) Regelungsvorschläge in Deutschland}

Mit dem Entwurf der Grünen ${ }^{184}$ und des Landes NRW ${ }^{185}$ liegen zwei ausformulierte Gesetzentwürfe vor. Diese sind bereits Gegenstand einer eingehenden kritischen Würdigung. ${ }^{186}$ Ich beschränke mich auf den gemeinsamen Kern der Vorschläge als exemplarische Modelle einer gesetzlichen Regulierung und übergehe im einzelnen wichtige Unterschiede ${ }^{187}$ und die damit zusammenhängenden unions- ${ }^{188}$ und verfassungsrechtlichen Probleme: ${ }^{189}$ Die Entwürfe sehen vor, dass börsennotierte Aktiengesellschaften ${ }^{190}$ eine geschlechtsneutral formulierte Mindestquote zu gewährleis-

180 Art. 5 Loi no. 2011-103 (Fn. 179).

181 Art. L225-18-1 Code de commerce idF des Gesetzes Nr. 2011-103 (Fn. 179).

182 Art. L225-45 Code de commerce idF des Gesetzes Nr. 2011-103 (Fn. 179).

183 Gesetz v. 12.7.2011 No. 120: Modifiche al testo unico delle disposizioni in materia di intermediazione finanziaria, di cui al decreto legislativo 24 febbraio 1998, n. 58, concernenti la parita' di accesso agli organi di amministrazione e di controllo delle societa' quotate in mercati regolamentati; G.U. no. 174 v. 28.7.2011, erhältlich unter http://www.gazzettaufficiale.it/.

184 Fn. 15.

185 Fn. 16.

186 Bachmann, ZIP 2011, 1131, $1134 \mathrm{ff}$.

187 Dazu näher Bachmann, ZIP 2011, 1131, 1135 ff.

188 Dazu Rolfs/Schmid/Witschen, Gleichberechtigte Vertretung der Geschlechter in Aufsichtsräten - Gemeinschaftsrechtliche Rahmenbedingungen -, http://www.sinus-institut.de/fileadmin/dokumente/ downloadcenter/Soziales_und_Umwelt/Gutachten_1_Gleichberechtigte_Vertretung_der_Geschlechter_in_Auf-sichtsraeten.pdf (zuletzt besucht: 23.8.2011), $19 \mathrm{ff}$.

189 Eingehend zu gleichheits- und freiheitsrechtlichen Aspekten staatlicher Quotenregelungen Papier/ Heidebach, ZGR 2011, 305, 314 ff, 323, die eine Quotenregelung im Wesentlichen für verfassungskonform erachten. Dagegen sieht Sachs, ZG 2012 (Heft 1) unter II 2 in einer staatlichen Quotenvorgabe einen Verstoß gegen Art. 3 Abs. 2 S. 1 und Abs. 3 S. 1 GG, der nicht über Art. 3 Abs. 2 S. 2 GG rechtfertigungsfähig sei. Ossenbühl, NJW 2012, 417 beschränkt sich im Kern auf die Untersuchung eines Modells regulierter Selbstregulierung und seine Ausführungen können daher nur mit Vorsicht auf ein Modell staatlicher Regulierung übertragen werden. Vgl. zur Diskussion auch die kursorischen Stellungnahmen bei François-Poncet/Deilmann/Otte, NZG 2011, 450, 453 ff; Spindler/ Brandt, NZG 2011, $401 \mathrm{ff}$ und Wieland, NJW 2010, $2408 \mathrm{ff}$.

190 Zum Kreis potentieller Adressaten einer staatlicher Regulierung eingehend Langenbucher, JZ 2011, 1039, 1039-1042. 
ten haben. Diese beträgt zunächst $30 \%$, steigt aber nach 2 bzw. 5 Jahren auf $40 \%$. Das Geschlecht des Kandidaten ist nicht persönliche Voraussetzung für seine/ihre Mitgliedschaft im Aufsichtsrat. Die Quote ist eine objektive Besetzungsregel, die eine qualifizierte Anforderung an die Gesamtzusammensetzung des Aufsichtsrats stellt. ${ }^{191}$ Daher muss der Aufsichtsrat bei der Zusammenstellung des Wahlvorschlags sicherstellen, dass die Hauptversammlung die Möglichkeit hat, einen geschlechtergerecht besetzten Aufsichtsrat zu bestellen. ${ }^{192}$ Der NRW-Entwurf regelt auch den eigentlichen Wahlvorgang: ${ }^{193}$ Danach ist eine Person nur dann gewählt, wenn mit der konkreten Wahl die gesetzliche Mindestanzahl der Angehörigen eines Geschlechts nicht unterschritten wird. Großer Diskussionsbedarf besteht bei den Rechtsfolgen: ${ }^{194}$ Soll der fehlerhafte Wahlbeschluss sanktionslos bleiben, zur Anfechtbarkeit führen ${ }^{195}$ oder nichtig ${ }^{196}$ sein ${ }^{197}$ Regelungsbedürftig sind auch die Auswirkungen auf die Beschlüsse eines gesetzwidrig besetzten Aufsichtsrats. ${ }^{198}$ Angesichts der bereits bei $\$ 100 \mathrm{Abs.} 5 \mathrm{AktG}$ unklaren Rechtslage muss man sicherstellen, dass die Rechtsfolgen einer mit der Quotenregelung inkongruenter Besetzung des Aufsichtsrats ausdrücklich geregelt werden. ${ }^{199}$

\section{c) Instrumentalisierung des Verbandsrechts?}

Mit einer Einheitsquote instrumentalisiert das politische System das Verbandsorganisationsrecht, um über das Recht das Wirtschaftssystem zu steuern. Damit es zur Interferenz dieser drei Teilsysteme kommt, bedarf es zweier struktureller Kopplungen: Rechtssystem und politisches System sind über den Begriff der „Verfassung“ gekoppelt. ${ }^{200}$ Komplizierter ist die Kopplung zwischen dem Recht und der Wirtschaft. Das Recht stellt der Wirtschaft mit der Körperschaft und ihrer Organisationsverfassung eine Struktur zur Verfügung, Kommunikationsbeziehungen der Akteure untereinander (Gesellschafter) und des daraus entstehenden Subsystems (Aktiengesellschaft) zu anderen Subsystemen zu organisieren und dadurch zu stabilisieren. Die Definitionsgewalt darüber liegt beim Recht. ${ }^{201}$ Es bestimmt, wer Aufsichtsrat sein kann und wer darüber bestimmt, wer zum Aufsichtsrat gewählt wird. Dieses

191 Vorbild dafür ist $\$ 100$ Abs. 5 AktG, dazu Staake, ZIP 2010, 1013, 1018 f; Wind/Klie, DStR 2010, 1339.

192 Vgl. zum ähnlichen Problem bei $\$ 100$ Abs. 5 AktG: Nowak, BB 2010, 2423, 1425.

193 Siehe dazu eingehend den NRW-Gesetzentwurf, BR-Drs. 87/11, S. 35 ff.

194 Siehe dazu Weller, Wie Quoten juristisch durchgesetzt werden können, FAZ v. 8.6.2011, S. 19; Bachmann, ZIP 2011, 1131, 1138; eingehend Langenbucher, JZ 2011, 1038, 1044-1046.

195 So der Vorschlag von Langenbucher, JZ 2011, 1039, $1045 \mathrm{f}$.

196 So der Entwurf der Grünen, BT-Drs. 17/3296, 8 f.; kritisch Bachmann, ZIP 2011, 1131, 1138.

197 Vgl. zum ähnlichen Problem bei $\$ 100$ Abs. 5 AktG Gruber, NZG 2008, 12, 14 ff; Widmann, BB 2009, 2602, 2602 ff; Nowak, BB 2010, 2423, 2425 ff; Staake, ZIP 2010, 1013, 1018 ff; Wind/Klie, DStR 2010, 1339, $1340 \mathrm{ff}$.

198 Vgl. dazu den Entwurf der Grünen, BT-Drs. 17/3296, 9.

199 Langenbucher, JZ 2011, 1038, 1045.

200 Luhmann, Das Recht der Gesellschaft, 1993, 468 ff. 
„Angebot“ wird im Wirtschaftssystem aufgegriffen, „solange der Rechtsdiskurs die strukturellen Kopplungen nicht überbeansprucht". ${ }^{202}$ Dafür sorgt im Ausgangspunkt das Rechtssystem selbst, indem es mit der Präferenzautonomie und ihrer verfassungsrechtlichen Absicherung sicherstellt, dass die Wahl des geeigneten Kandidaten als eigene Leistung des Wirtschaftssystem erscheint.

Das liberale Recht akzeptiert die Ergebnisse dieses Wettbewerbs, solange sie aus einem fairen und chancengleichen Verfahren hervorgegangen sind. „Chancengleichheit" ist allerdings ein schillernder Begriff. ${ }^{203}$ Gleichheit (equality) und Chancen im Wettbewerb (opportunities) stehen im Spannungsverhältnis. Man kann das so auflösen, dass Chancengleichheit bereits dann besteht, wenn alle Akteure nach denselben Regeln spielen und der Leistungsfähigste „gewinnt“. Diese starting gate-theo$r y^{204}$ programmiert die Rechtsoperationen so, dass sie jedes Ergebnis dieses Wettbewerbs als gleichheitskonform akzeptieren. Der Zweck des Wettbewerbs als Entdeckungsverfahren besteht aber darin, bestehende Ungleichheiten offenzulegen, um dadurch den Leistungsfähigsten herauszufiltern. Im zwangsläufig ungleichen Ergebnis realisieren sich die ungleichen Ausgangspositionen der Kandidaten. Das Argument der Geschlechtergerechtigkeit sensibilisiert das Recht für die damit zusammenhängenden Ungleichheiten. Damit es sicherstellen kann, dass Frauen bei der Berücksichtigung der Auswahlprozesse tatsächlich gleiche Chancen haben, muss man Chancengleichheit vom Ergebnis her konzipieren. Dazu bietet sich die „Strategie der Chancen wahrenden Auswahlbeeinflussung “205 an. Danach ist die Quote nicht das Ergebnis, sondern „ein Mittel zur tatsächlichen Verwirklichung der Chancengleichheit im individuellen Auswahlverfahren. Wenn sich dann der Frauenanteil tatsächlich erhöht, ist dies die Folge nunmehr verwirklichter Chancengleichheit." ${ }^{206}$ Wie der EuGH in der Rs. Marschall zutreffend feststellte, „bedeutet allein die Tatsache, daß zwei Bewerber unterschiedlichen Geschlechts gleich qualifiziert sind, nicht, daß sie gleiche Chancen haben. “207 Die Tendenz Männer zu bevorzugen, hängt, so der Gerichtshof, „vor allem mit einer Reihe von Vorurteilen und stereotypen Vorstellungen über die Rolle und die Fähigkeiten der Frau im Erwerbsleben“ zusam-

201 Vgl. dazu - allerdings mit Bezug zum Vertragsmechanismus - Teubner, Steuerung durch plurales Recht (Fn. 19), 528, $541 \mathrm{ff}$.

202 Teubner, Steuerung durch plurales Recht (Fn. 19), 528, 542.

203 Vertiefend dazu Grünberger, Personale Gleichheit (Fn. 1), 470 ff, $736 \mathrm{ff}$.

204 Der Begriff stammt von Dworkin, Sovereign Virtue, 2000, $87 \mathrm{f}$.

205 Ossenbühl, NJW 2012, 417, 419. Vgl. dazu auch Papier/Heidebach, ZGR 2011, 305, 320 ff, die aufgrund der Besonderheiten der Gremienbesetzung zugunsten einer „starren“, also nicht leistungsbezogenen Quote plädieren.

206 Ossenbühl, NJW 2012, 417, 419.

207 EuGH Urt. v. 11.11.1997, Rs. C-409/95 - Marschall v. Land Nordrhein-Westfalen, Slg. 1997, I-6363, Rn. 30. 
men. ${ }^{208}$ Will man diesen Zusammenhang durchbrechen, muss das Recht die Ergebnisse des Wettbewerbs nicht ohne weiteres akzeptieren, wenn er aus strukturellen Gründen nicht zu einer Annäherung der betroffenen Gruppen führt. Jede Quote führt zur Modifikation des Auswahlverfahrens. Damit beeinflusst das Recht die Präferenzbildung des Verbandes. Diese Beeinflussung ist nur erfolgreich, wenn sie an Operationen im Wirtschaftssystem anknüpfen kann. Dafür leistet der Begriff „Diversity " Hilfestellung. Seine Verwendung im politischen System ist daher kein Zufall. Er ermöglicht eine strukturelle Kopplung beider Systeme. Dabei geht man in der Politik davon aus, dass ein geschlechtergerecht besetztes Aufsichtsorgan für das Unternehmen ökonomisch vorteilhaft ist. Diese Annahme ist zwar möglich, aber sie ist nicht unumstritten. ${ }^{209}$ Eine Einheitsquote differenziert nicht zwischen Unternehmen mit oder solchen ohne Governanceproblemen. ${ }^{210}$ Sie maßt sich damit ein Wissen an, dass in der Wirtschaft selbst erst noch zu erzeugen ist. Das schwächt ihren regulativen Effekt. ${ }^{211}$

\section{d) Regulierungsversagen?}

Damit besteht die Gefahr, dass das Band der strukturellen Kopplung von Wirtschaft und Recht reißt. ${ }^{212}$ Jeder Eingriff in Funktionssysteme der Gesellschaft kann zum Regulierungsversagen führen. ${ }^{213}$ Das ist der Fall, wenn das regulierte System - hier die Wirtschaft - mit Nichtbeachtung reagiert. Derart symbolische Gesetzgebung führt langfristig zur Legitimationskrise von Politik und Recht. Ob es dazu kommt, hängt davon ab, ob eine staatlich vorgegebene Quotenregelung als Rechnungsposten „gelesen“214 wird, der man nicht zwingend folgen muss. Das wiederum hängt entscheidend vom Sanktionsmechanismus ab. Die spanische Regelung empfiehlt sich dabei als negatives, die norwegische Quote als positives Beispiel.

Eine effektive Sanktionierung einer Quotenregel könnte nicht intendierte negative Folgen innerhalb des Wirtschaftssystems haben. Eine Folgenabschätzung kann nicht sicher vorhersagen, wie sich die Verrechtlichung einer vormals informell geregelten Sphäre der Personalfindung auf die Besetzung und Arbeitsweise des Aufsichtsrats auswirkt. Dabei spielt das „Poolproblem“ eine wichtige Rolle: Die Anzahl geeigneter

208 EuGH Urt. v. 11.11.1997, Rs. C-409/95 - Marschall v. Land Nordrhein-Westfalen, Slg. 1997, I-6363, Rn. 29.

209 Siehe oben III 2c) (1).

210 Adams/Ferreira, 94 J. of Financial Economics 291 (2009).

211 Vgl. die Kritik an starren Quotenregelungen Roundtable Berlin Center of Corporate Governance, DB 2010, 2786.

212 Zum Problem Teubner, Steuerung durch plurales Recht (Fn. 19), 528, 542.

213 Dazu Teubner, Quaderni Fiorentini (13) 1984, 109, 124 ff; Callies, Die Steuerungskrise - jetzt auch im Privatrecht?, FS G. Teubner, 2009, 464, 469 ff.

$214 \mathrm{Zu}$ den verschiedenen Lesarten siehe Teubner, Steuerung durch plurales Recht (Fn. 19), 528, $531 \mathrm{ff}$. 
Kandidatinnen sei (noch) nicht groß genug, um die Quoten zu erfüllen. ${ }^{215}$ Die Quote verhindere, dass eigentlich besser qualifizierte Männer in den Aufsichtsrat gewählt würden. Das Recht zwinge das Unternehmen, unwirtschaftlich zu handeln. Das basiert auf der Prämisse, dass es für die Qualifikation als Aufsichtsrätin erforderlich sei, Unternehmenserfahrung in Führungspositionen, am besten im Vorstand einer AG gesammelt zu haben. Führungsverantwortung ist zwar eine regelmäßig notwendige, eine langjährige Vorstandsmitgliedschaft dagegen keine faktische Voraussetzung. ${ }^{216}$ „Es gibt keinen überzeugenden Grund dafür, dass sich die Auswahl auf diesen Personenkreis beschränken muss. "217 Im Übrigen lässt sich das Problem sofern es denn existiert - mit einer Härteklausel lösen. Nach dem NRW-Entwurf kann das Unternehmen im Einzelfall von der Quote abweichen, wenn trotz rechtzeitig ergriffener Maßnahmen zur Förderung und Gewinnung von Führungskräften beider Geschlechter nicht ausreichend Kandidaten eines Geschlechts zur Verfügung standen. ${ }^{218}$ Wird ein entsprechender Beschluss der Hauptversammlung angefochten, muss die Gesellschaft darlegen, welche Maßnahmen sie unternommen hat, um eine hinreichende Anzahl von Frauen zu finden, die zur Übernahme eines Aufsichtsratsmandates bereit und qualifiziert sind. ${ }^{219}$ Das Recht zwingt das Unternehmen, in einen Rechtfertigungsdiskurs einzutreten. Das Rechtfertigungsmodell von Ungleichbehandlungen im Privatrecht ${ }^{220}$ ermöglicht Interferenzen zwischen den Systemen: Es erlaubt dem Recht, auf Operationen des Wirtschaftssystems Rücksicht zu nehmen. Wenn es im Einzelfall tatsächlich keine Frau geben sollte, die den Job so gut wie ein bereit stehender Mann machen kann, nimmt das Recht seinen Regulierungsanspruch zurück. Damit stellt das Rechtfertigungsmodell sicher, dass das Band der strukturellen Kopplung nicht reißt. Es stellt aber Bedingungen daran. Das Unternehmen muss lang- und mittelfristige Bemühungen im Bereich der Förderung und Qualifizierung des Führungskräftenachwuchses unternommen haben, um über ausreichend weibliche, zur Übernahme eines Aufsichtsratsmandates qualifizierte Führungskräfte verfügen zu können. ${ }^{221}$ Das ist ein innovatives Element: Das Recht belohnt die Investition des einzelnen Unternehmens in die Zukunft des gesamten Systems, indem es das Unternehmen von der Verantwortung für den gegenwärtigen Zustand des Systems entlastet.

215 Redenius-Hövermann, ZIP 2010, 660, 665; Schladebach/Stefanopoulou, BB 2010, 1042, 1046; Peltzer, NZG 2011, 281, 283. Eine einheitliche Quote auch für Unternehmen in Branchen, in denen Frauen nur in geringer Zahl vertreten sind, halten Papier/Heidebach, ZGR 2011, 305, $318 \mathrm{ffür}$ verfassungsrechtlich problematisch.

216 Vgl. die empirischen Ansätze bei Rudolph, Frauen in Aufsichtsräten (Fn. 144), 35, 43.

217 Ossenbübl, NJW 2012, 417, 421.

218 BR-Drs. 87/11, S. 22.

219 BR-Drs. 87/11, S. 34.

220 Dazu eingehend Grünberger, Personale Gleichheit (Fn. 1), $891 \mathrm{ff}$.

221 BR-Drs. 87/11, S. 34. 


\section{Regulierte Selbstregulierung}

Die dritte Möglichkeit, den Anteil von Frauen in Aufsichtsräten und Vorständen zu steigern, bietet ein Modell „regulierter Selbstregulierung“.222 Dieser „Verbundbegriff“ 223 bezeichnet eine Kooperation zwischen privater Wissenserzeugung, privater Standardisierung und Regelbildung einerseits („Selbstregulierung“) und staatlicher (Rahmen-)Regelung anderseits. Der Staat reagiert auf den Zwang zur Entscheidung unter Ungewissheitsbedingungen, indem er an Methoden und Modelle der Erzeugung von Wissen nicht-staatlicher Akteure in den Funktionssystem der Gesellschaft anknüpft, „die es erlauben, Hypothesen zu formulieren und zu erproben - oder Regulierungen stufenweise unter der Erwartung der Erzeugung neuen Wissens durch die Entscheidungsstrategie selbst zu formulieren. "224 Auf diesem Ansatz basieren die Diversity-Empfehlungen im Deutschen Corporate Governance Kodex (DCGK)225 und der Vorschlag einer unternehmensspezifischen flexiblen Frauenquote („FlexiQuote“).

\section{a) Deutscher Corporate Governance Kodex}

\section{(1) „Rechtsnatur“ von Empfehlungen des DCGK}

Der DCGK enthält drei Gruppen von Bestimmungen, ${ }^{226}$ von denen hier nur die „Empfehlungen “ interessieren. Das sind Verhaltensmaßstäbe für die Unternehmensleitung und Unternehmensüberwachung, die nach Auffassung der in der Regierungskommission Deutscher Corporate Governance Kodex repräsentierten privaten Akteure im Wirtschaftssystem ${ }^{227}$ mittlerweile zur Best-Practice zählen. ${ }^{228}$ Die Empfehlungen kondensieren nach ihrem Selbstverständnis das systemintern gewonnene Wissen und formulieren es als maßstabsetzende soziale Praxis. Daran sollten sich die Organe börsennotierter Gesellschaften bei der Leitung und Überwachung ihres Unternehmens orientieren. Die Beachtung der Kodex-Empfehlungen unterliegt nach traditioneller Auffassung der freien Entscheidung von Vorstand und Aufsichtsrat. ${ }^{229}$ Die Gesellschaften können davon abweichen. Das ermöglicht ihnen, bran-

222 Zur Begriffsgeschichte siehe Voßkuble, „Regulierte Selbstregulierung“ - Zur Karriere eines Schlüsselbegriffs, in: Regulierte Selbstregulierung als Steuerungskonzept des Gewährleistungsstaates, 2001, 197 ff; zum Konzept näher Eifert in: Hoffmann-Riehm/Schmidt-Aßmann/Voßkhule, Grundlagen des Verwaltungsrechts, Bd. I, Bd 1., 2006, $\$ 19$ Rn. 52 ff.

223 Schmidt-Aßmann, Regulierte Selbstregulierung als Element verwaltungsrechtlicher Systembildung, in: Regulierte Selbstregulierung als Steuerungskonzept des Gewährleistungsstaates, 2001, 253, $254 \mathrm{f}$.

224 Ladeur, Die Regulierung von Selbstregulierung und die Herausbildung einer „Logik der Netzwerke“, in: Regulierte Selbstregulierung als Steuerungskonzept des Gewährleistungsstaates, 2001, 59, $76 \mathrm{f}$.

225 Ob der DCGK eine Form der Selbstregulierung ist, ist nicht ganz unbestritten, dazu Buck-Heeb/ Dieckmann, Selbstregulierung im Privatrecht, 2010, $99 \mathrm{f} \mathrm{mwN}$.

226 Statt vieler Kirschbaum/Wittmann, JuS 2005, 1062, 1063 f.

227 Siehe Seibert, BB 2002, 581, 582; kritisch zur Zusammensetzung Rucht, Der deutsche Corporate Governance Kodex: Erfolgreiche Selbstregulierung?, in: Imbusch/Rucht (Hrsg.), Profil oder Gemeinwohl?, 2007, 131, $141 \mathrm{ff}$.

228 Vgl. BT-Drs. 14/8789, S. 21

229 OLG München NZG 2009, $509 \mathrm{f}$. 
chen- oder unternehmensspezifische Bedürfnisse zu berücksichtigen. Die Empfehlungen sind keine staatlichen Rechtsnormen. ${ }^{230}$ In der traditionellen Normenhierarchie des Verbandsrechts sind die Empfehlungen soft law. Es ist Normsetzung privater Akteure. ${ }^{231}$ Sie können damit andere private Akteure aber nicht rechtlich binden, weil ihnen dazu die Kompetenz fehlt. Sie sind deshalb aber nicht völlig unverbindlich. Die Empfehlungen erfüllen nämlich eine „harte“ Definition von soft law. ${ }^{232}$ Sie erlangen über $\mathbb{S} 161 \mathrm{AktG}$ als staatlicher „Hintergrundregelung“ rechtliche Relevanz. ${ }^{233}$ Das Zusammenspiel klassischer Regulierung und privater Normsetzung kennzeichnet die Empfehlungen im DCGK mit dem Motto: „Entsprich oder erkläre, warum du nicht entsprichst! “234 Die Erklärungspflicht soll Aktionäre und Kapitalmarktteilnehmer darüber informieren, ob sich das Unternehmen an die Verhaltensstandards hält, die im Kodex niedergelegt sind. ${ }^{235}$ Das beruht auf der - nicht zweifelsfreien ${ }^{236}$ - Annahme, dass der Kapitalmarkt auf Abweichungen von den Empfehlungen reagiert. ${ }^{237}$ Damit baut der Kodex zunächst auf eine immanente Sanktionierung im Wirtschaftssystem. Die unterlassene und die unzutreffende Erklärung erzeugen aber auch Irritationen im Rechtssystem. ${ }^{238}$ Vorstand und Aufsichtsrat ver-

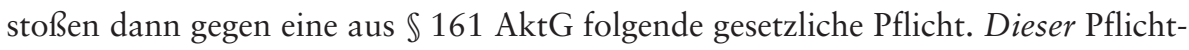
verstoß kann dazu führen, dass ein von der Hauptversammlung gefasster Entlas-

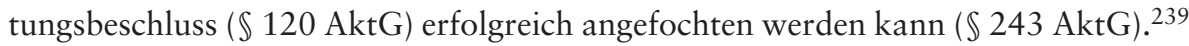

Der DCGK ist auf vier Ebenen ein Beispiel wechselseitiger Irritationen zwischen geschlossenen Teil- und Subsystemen der Gesellschaft: ${ }^{240}$ (1.) Der DCGK identifiziert

230 Dazu Ulmer, ZHR (166) 2002, 150, 158 ff; Hüffer, AktG, 9. Aufl., 2010, $\mathbb{1 6 1}$ Rn. 3; Spindler in: Schmidt/Lutter, AktG, 2. Aufl., 2010, \$161 Rn. 8.

231 Vgl. dazu Kirschbaum/Wittmann, JuS 2005, 1062, 1064 f; Ringleb in: Ringleb/Kremer/Lutter/Werder, DCGK, 4. Aufl., 2010, Vorbem. Rn. $51 \mathrm{ff}$, dort mit Nachweisen zur Gegenansicht.

232 Vgl. Orly, 89 Minns. L. Rev. 342, 389-90.

$233 \mathrm{Zu}$ den hier nicht thematisierten verfassungsrechtlichen Problemen dieser Konstruktion kritisch Hoffmann-Becking, Deutscher Corporate Governance Kodex - Anmerkungen zur Zulässigkeit, Inhalt und Verfahren, FS Hüffer, 2010, 337 ff; Hüffer, AktG (Fn. 230), \$161 Rn. 4; Spindler in: Schmidt/Lutter, AktG (Fn. 230), $\$ 161$ Rn. 11; verteidigend dagegen Ringleb in: Ringleb/Kremer/ Lutter/Werder, DCGK (Fn. 231), Vorbem. Rn. 51 ff.

234 Grundlegend Baums, Bericht der Regierungskommission Corporate Governance, 2001, Rn. 8; zur Berechtigung von comply or explain näher Ringleb in: Ringleb/Kremer/Lutter/Werder, DCGK (Fn. 231), Vorb. Rn. 47.

235 Siehe BT-Drs. 14/8789, S. 21.

236 Siehe Nowak/Rott/Mahr, ZGR 2005, 252.

237 Bericht der Regierungskommission Deutscher Corporate Governance Kodex an die Bundesregierung, November 2010, http://www.corporate-governance-code.de/ger/download/16122010/ Governance_Bericht_Nov_2010.pdf, S. 11 [im Folgenden „Bericht Regierungskommission DCGK“].

$238 \mathrm{Zu}$ den rechtlichen Konsequenzen einer Nichtbefolgung siehe Hüffer, AktG (Fn. 230), \$161 Rn. 25 ff; kritisch zur „Verrechtlichung“ des Kodex Bachmann, Private Ordnung, 2006, 46.

239 Siehe dazu grundlegend BGHZ 180, 9, Rn. 19 ff; vertiefend Sester in: Spindler/Stilz, AktG, 2. Aufl., Bd. 2, 2010, $\$ 161 \mathrm{Rn} .61 \mathrm{ff}$.

240 Vgl. dazu Teubner, FS Hopt, 2010, 1449, 1465 f, der das Verhältnis der Netzwerke mit dem Begriff „Ultrazyklus“ erfassen möchte, sich allerdings auf das Verhältnis staatlicher und unternehmenseigener Codes beschränkt. 
soziale Praktiken des Wirtschaftssystems und setzt diese dort als optionalen Verhaltensmaßstab fest. Er formuliert daher rechtliche Regeln besonderer Art: Verhaltensappell und informelle Empfehlung, ohne Anspruch auf Verbindlichkeit und Sanktion. Kurz: ein Regelungsangebot an die Subsysteme. (2.) Die Aktiengesellschaft akzeptiert diese Empfehlung, wenn sie diese in einem verbandsinternen Code umsetzt, der Meta-Regeln für die rechtlichen und ökonomischen Kommunikationen im Verband setzt. ${ }^{241}$ Implementiert der Verband die Empfehlungen nicht auf diese Weise, bleibt der normierte soziale Standard des Wirtschaftssystems im Subsystem wirkungslos. Wenn die Subsysteme dem DCGK reihenweise die Gefolgschaft versagen, wird dieser zu neuen Lernprozessen gezwungen. ${ }^{242}$ Der Kodex rezipiert diese Weigerung als neues Wissen und wird die Empfehlungen der von ihm festgestellten Akzeptanzbereitschaft anpassen, damit er seine Akzeptanz nicht insgesamt in Frage stellt. (3.) $\$ 161 \mathrm{AktG}$ verpflichtet börsennotierte Unternehmen zur wahrheitsgemäßen Stellungnahme. Das ist klassisches hard law. Es stellt dem Verband drei Erklärungsvarianten zur Auswahl:243 (a) Die Empfehlungen werden vollumfänglich beachtet. (b) Wurde und wird teilweise abgewichen, ist das offenzulegen und zu begründen. (c) Der Verband kann sie theoretisch auch gänzlich ablehnen. ${ }^{244}$ Praktisch ist das nur relevant, wenn das Unternehmen stattdessen auf einen eigenen Code of best practice verweist. ${ }^{245}$ Das Unternehmen muss diese Entsprechenserklärung veröffentlichen ( $\mathbb{1} 161$ Abs. 2 AktG, $\mathbb{} 289$ a Abs. 2 Nr. 1 HGB). Damit erleichtert staatliches hard law den beschriebenen Lernprozess im Wirtschaftssystem. Der Verband muss seiner Umwelt mitteilen, für welche Erklärungsvariante er sich entschieden hat. (4.) Darin erschöpft sich die Bedeutung des $\$ 161 \mathrm{AktG}$ noch nicht. Die Norm enthält zwar keine im Rechtssystem operierende Vermutung zugunsten der Kodexempfehlungen. ${ }^{246}$ Man verkennt allerdings die Interferenz zwischen Recht und Ökonomie, wenn man die Empfehlungen als „unverbindliche Denkanstöße“ 247 qualifiziert, „die zur kritischen Analyse ihrer Anwendbarkeit auf die spezifische Situation des betroffenen Unternehmens anregen sollen “. ${ }^{248}$ Das könnte man auch mit einer opt-in-Regel erreichen. $\$ 161 \mathrm{AktG}$ ist aber als opt-out-Regel ausgestaltet: Nicht die Befolgung, sondern die Abweichung im Detail oder die Nichtanwendung sind begründungspflichtig. Damit bezieht das Recht inhaltlich Position: Es übernimmt die Auffassung, dass es sich tatsächlich um die best practice börsennotierter Unternehmen handelt.

241 Dazu oben IV 1 c).

242 Siehe dazu die Evaluation der Kodexbefolgung, Bericht Regierungskommission DCGK (Fn. 237), S. $13 \mathrm{ff}$.

243 Vgl. dazu Hüffer in: Hüffer, AktG (Fn. 230), $\$ 161$ Rn. 16 ff, 21; Spindler in: Schmidt/Lutter, AktG (Fn. 230), \$161 Rn. $31 \mathrm{ff}$.

244 Zu dieser Möglichkeit Ulmer, ZHR (166) 2002, 150, 172.

245 Hüffer in: Hüffer, AktG (Fn. 230), $\$ 161$ Rn. 18.

246 Zum Vergleich beider Ansätze siehe Ulmer, ZHR (166) 2002, 150, $161 \mathrm{ff}$.

247 Bachmann, ZIP 2011, 1131, 1132.

248 Ringleb in: Ringleb/Kremer/Lutter/Werder, DCGK (Fn. 231), Vorbem. Rn. 63. 
Damit „empfiehlt“ $\$ 161$ AktG die Befolgung der Regel, ohne dazu zu zwingen. Begründungspflichten wirken aber auf regelkonformes Verhalten hin. Damit sorgt die Norm als soft law dafür, dass die Empfehlungen im Wirtschaftssystem zur default rule der Verbandsorganisation werden.

\section{(2) Diversity-Empfehlungen}

Der im Jahr 2010 ergänzte DCGK empfiehlt die angemessene Beteiligung bzw. Berücksichtigung von Frauen in Führungspositionen auf drei Ebenen: (1.) der Zusammensetzung des Aufsichtsrats, (2.) der Bestellung des Vorstandes und (3.) der Personalverantwortung des Vorstandes. Das übergreifende Ziel dieser Empfehlungen besteht darin, die Qualität unternehmerischer Entscheidungen zu steigern. Grundlage dafür ist die These, dass Unternehmen, deren Organe und Mitarbeiterstruktur Vielfalt in persönlich-fachlicher Hinsicht - dazu zählt auch das Geschlecht - aufweisen, zur Verbesserung des Unternehmenswerts beitragen. ${ }^{249}$ Das ist im Kern der Business Case für Diversität. ${ }^{250}$ Die Empfehlungen des DCGK kombinieren mit den drei Ebenen einen bottom-to-top mit einem top-to-bottom-Ansatz. Beide stehen unter dem sehr zuversichtlichen Motto: „Reflexion, Selbstregulierung und Transparenz statt Automatismus und starrer Quoten“.251

\section{aa) Führungspositionen unterhalb des Vorstandes}

„Der Vorstand soll bei der Besetzung von Führungspositionen ${ }^{252}$ im Unternehmen auf Vielfalt (Diversity) achten und dabei insbesondere eine angemessene Beteiligung von Frauen anstreben.“ (Nr. 4.1.5 DCGK) Damit soll „zunächst mehr Frauen die Möglichkeit gegeben werden, in Führungspositionen Erfahrungen zu sammeln, um sich für einen Vorstandsposten zu qualifizieren und damit auch in die Voraussetzungen für die Wahrnehmung eines Aufsichtsratsmandats hineinzuwachsen. “253 Der zweite Begründungsansatz überrascht. Die Vorstandstätigkeit ist weder eine gesetzliche Voraussetzung für ein Aufsichtsratsmandat, ${ }^{254}$ noch im Wirtschaftssystem selbst als präferenzleitendes Kriterium anerkannt. ${ }^{255}$ Diese Erklärung lässt sich nur schwer mit dem allgemeinen Diversitätsansatz vereinbaren, dessen Ziel es ist, den Kandidatenpool für Aufsichtsräte über die klassische Besetzung mit Vorständen hinaus zu erweitern. ${ }^{256}$

$249 \mathrm{Zu}$ den Grundlagen Aretz/Hansen, Diversity und Diversity Management im Unternehmen, 2002.

250 S.o. III 2 c).

251 Weber-Rey/Handt, NZG 2011, 1, 2.

252 Zum Begriffsverständnis Deilmann/Albrecht, AG 2010, 727, 734; Hecker/Peters, BB 2010, 2251, 22554; Henze/Rosch, ArbRAktuell 2010, 573, 734; Ringleb/Kremer/Lutter/Werder, NZG 2010, 1161, Rn. 661 c.

253 Bericht Regierungskommission DCGK (Fn. 237), S. 32.

254 Dazu oben IV 1 a.

255 Siehe Rudolph, Frauen in Aufsichtsräten (Fn. 144), 35 und Roundtable Berlin Center of Corporate Governance, DB 2010, 2786, $2787 \mathrm{f}$.

256 Dazu Weber-Rey, DB 2010, 41 f; Dauner-Lieb, DB 2010, 45, 46. 


\section{bb) Besetzung des Vorstandes}

„Bei der Zusammensetzung des Vorstands soll der Aufsichtsrat auch auf Vielfalt (Diversity) achten und dabei insbesondere eine angemessene Berücksichtigung von Frauen anstreben." (Nr. 5.1.2 S.2 DCGK) Wie bereits auf Stufe (1) ist eine angemessene Beteiligung von Frauen „anzustreben“. Dadurch wird verdeutlicht, dass es eines von mehreren Zielen bei der Besetzung des Vorstandes sein soll. ${ }^{257}$ Im Ausgangspunkt respektiert der DCGK die Präferenzentscheidung und damit die Eigenrationalität des Subsystems Aktiengesellschaft. Er konzipiert Gender Diversity lediglich - aber immerhin - als einen dabei zwingend zu berücksichtigenden Gesichtspunkt. Das Kriterium der „Angemessenheit“ überlässt es dem Aufsichtsrat, darüber zu entscheiden, welche der zahlreichen möglichen Maßnahmen ${ }^{258}$ zur Frauenförderung im Interesse des Unternehmens liegen. ${ }^{259}$ Diese Konzeption wäre mit einer Frauenquote für den Vorstand unvereinbar. ${ }^{260}$ Der Kodex gibt also lediglich das „Ob“ der Berücksichtigung vor, überlässt das „Wie“ aber grundsätzlich dem Verband. Unklar ist, ob er diesbezüglich von einem Mindestinhalt ausgeht: Genügt es, wenn die Organe beschließen, in Zukunft Frauen „irgendwie“ angemessen zu berücksichtigen? ${ }^{261}$ Oder muss der Aufsichtsrat den Ist-Zustand analysieren und auf dieser Grundlage selbstbestimmte Kriterien für die Förderung von Frauen entwickeln?262 Muss er auch entsprechende Bemühungen in diese Richtung unternehmen?263 Von der Antwort darauf hängt es ab, wie man die Steuerungsfähigkeit des DCGK einschätzt. ${ }^{264}$

\section{cc) Besetzung des Aufsichtsrats}

„Der Aufsichtsrat soll für seine Zusammensetzung konkrete Ziele benennen, die unter Beachtung der unternehmensspezifischen Situation [...] Vielfalt (Diversity) berücksichtigen. Diese konkreten Ziele sollen insbesondere eine angemessene Beteiligung von Frauen vorsehen." (Nr. 5.4.1. S. 2 und 3 DCGK) Prämisse dafür ist die These, wonach nur eine heterogene Zusammensetzung des Aufsichtsrats gewährleiste, dass dieser seine unternehmerischen Entscheidungen und seine Kontrollfunktion gegenüber dem Vorstand effizient wahrnehmen kann. ${ }^{265}$ Ziel der Empfehlung ist eine Qualitätssteigerung des Aufsichtsrats in seiner Gesamtheit und eine Erwei-

257 Ringleb/Kremer/Lutter/Werder, NZG 2010, 1161, Rn. 939 c.

258 Dazu Kocher, BB 2010, 264, 265; Ringleb/Kremer/Lutter/Werder, NZG 2010, 1161, Rn. 939 d.

259 Keiluweit, DStR 2010, 2251, 2254; Schubert/Jacobsen, WM 2011, 726, 728.

260 Deilmann/Albrecht, AG 2010, 727, 734; Hecker/Peters, BB 2010, 2251, 2254; Henze/Rosch, ArbRAktuell 2010, 573, 574; Mense/Rosenhäger, GWR 2010, 311, 313; Ringleb/Kremer/Lutter/Werder, NZG 2010, 1161, Rn. 939 c.

261 Ringleb/Kremer/Lutter/Werder, NZG 2010, 1161, Rn. 939 d.

262 Schubert/Jacobsen, WM 2011, 726, 730.

263 Deilmann/Albrecht, AG 2010, 727, 734.

264 S.u. IV 3 a) (2) dd).

265 Vgl. Roundtable Berlin Center of Corporate Governance, DB 2010, 2786, 2787. 
terung des Kandidatenpools „außerhalb üblicher Netzwerke“.266 Das könne nicht mit einheitlichen Zielvorgaben erreicht werden. Vielmehr gehe es darum, den Unternehmen selbstbestimmte individuelle Lösungen zu ermöglichen, damit sie flexibel auf ihre konkreten Bedürfnisse reagieren könnten. ${ }^{267}$

Die abweichende Formulierung dieser Empfehlung fällt auf. Offensichtlich unterscheidet der DCGK zwischen der Präferenzautonomie des Verbandes bei der Besetzung operativer Positionen (Vorstand, Führungsebenen) einerseits und bei der Besetzung des Aufsichtsgremiums andererseits. Im Ausgangspunkt bleibt es bei der grundsätzlichen Aufgabenverteilung zwischen „Ob“ und „Wie“: Notwendig ist keine bestimmte sondern nur eine angemessene Beteiligung von Frauen. Was angemessen ist, hat der Aufsichtsrat unter Berücksichtigung des Unternehmensinteresses nach den Vorgaben der business judgment rule ( $\mathbb{S} 116$ S. 1 iVm $\mathbb{\$} 93$ Abs. 1 S. 2 AktG) ${ }^{268}$ festzulegen. ${ }^{269}$ Die Angemessenheit kann sich auf das Verhältnis zum Anteil der weiblichen Führungspersonen im Unternehmen, ${ }^{270}$ der Gesamtbelegschaft des Unternehmens ${ }^{271}$ oder der Kunden ${ }^{272}$ beziehen. ${ }^{273}$ Unklar ist, ob sie sich in mitbestimmten Unternehmen auf den gesamten Aufsichtsrat oder lediglich auf die Anteilseignervertreter bezieht. ${ }^{274}$

Bezüglich des „Wie“ setzt der DCGK aber Mindestanforderungen: Der Text verlangt zwar keine konkrete Quote für den Aufsichtsrat. Dieser muss aber konkrete Ziele benennen. Allgemeine Festlegungen genügen daher nicht, um der Empfehlung nachzukommen. ${ }^{275}$ Das effektivste Mittel zur angemessenen Berücksichtigung der Frauen ist der Wahlvorschlag des Aufsichtsrats. ${ }^{276}$ Dort ist der Platz, das Ziel einer erhöhten Frauenbeteiligung zu berücksichtigen. ${ }^{277}$ Das muss bei der Zielsetzung berücksichtigt werden. Ein konkretes Ziel kann nur eines sein, dessen Erreichen oder Nichterreichen innerhalb eines vorgegebenen Zeitrahmens nachprüfbar ist. Damit verlangt

266 Weber-Rey/Handt, NZG 2011, 1 f, 3.

267 Weber-Rey/Handt, NZG 2011, 1, 2.

268 Weiterführend Habersack, MünchKomm-AktG (Fn. 135), \$116 Rn. 39 ff.

269 Weber-Rey/Handt, NZG 2011, 1, 3 f.

270 Ringleb/Kremer/Lutter/Werder, NZG 2010, 1161, Rn. 1025 h.

271 Deilmann/Albrecht, AG 2010, 727, 730.

272 Vgl. Weber-Rey/Handt, NZG 2011, 1, 3.

273 Zu den Möglichkeiten näher Ringleb/Kremer/Lutter/Werder, NZG 2010, 1161, Rn. 1025 h.

274 Dazu Deilmann/Albrecht, AG 2010, 727, 730; zur Möglichkeit, die Zielvorgaben getrennt auszuweisen vgl. Ringleb/Kremer/Lutter/Werder, NZG 2010, 1161, Rn. 1025 k.

275 Keiluweit, DStR 2010, 2251, 2254; Ringleb/Kremer/Lutter/Werder, NZG 2010, 1161, Rn. 1025 g; Schubert/Jacobsen, WM 2011, 726, 728; Weber-Rey/Handt, NZG 2011, 1, 3.

276 Siehe Nr. 5.4.1 S. 4 DCGK: „Vorschläge des Aufsichtsrats an die zuständigen Wahlgremien sollen diese Ziele berücksichtigen."

277 Schubert/Jacobsen, WM 2011, 726, 730. 
der Kodex vom Aufsichtsrat, sich quantitative und zeitliche Vorgaben zu setzen. ${ }^{278}$ Wer sich der Empfehlung des Kodex anschließt, verpflichtet sich daher im Ergebnis dazu, eine Zielquote für das Unternehmen festzulegen. ${ }^{279}$ Solche Zielvorgaben sind als Teil eines begrenzten Konzepts zur Verwirklichung der Chancengleichheit auch rechtlich zulässig. ${ }^{280}$ Der genaue Zeitplan und die Höhe der Quote bleiben dem Verband überlassen. Er muss seine Festlegungen allerdings veröffentlichen (Nr. 5.4.1. S. 5 DCGK). ${ }^{281}$ Mit dieser Berichtspflicht aktiviert der Kodex die Umwelt des Verbandes, Druck auf die Benennung und Umsetzung der Ziele auszuüben. ${ }^{282}$ Allerdings verlangt der Kodex nicht, dass die Ziele auch erreicht werden müssen. ${ }^{283}$ Der Verband geht mit einer Entsprechenserklärung für die Zukunft ${ }^{284}$ das Risiko von Umsetzungsschwierigkeiten ein. Realisiert es sich, zwingt ihn das Rechtssystem nur zur Erklärung darüber, dass die konkreten Ziele nicht erreicht wurden. ${ }^{285}$ Erneut stellt sich das Problem der Mindestanforderungen: Genügt es, wenn der Aufsichtsrat die Zielverfehlung mit dem Poolproblem erklärt oder muss er zugleich darlegen, welche Maßnahmen der Verband insgesamt getroffen hat, dieses Poolproblem zu verkleinern?286

\section{dd) Durchsetzung}

Die Effektivität der Diversity-Empfehlungen hängt von der erfolgreichen Interferenz der unterschiedlichen Steuerungsebenen ab. Über den Begriff der Empfehlung sind die drei Kommunikationssysteme Kodex, Verband (AG) und Recht strukturell verkoppelt. Die jeweilige systeminterne Interpretation der im Kodex verwendeten Begriffe kann zu Irritationen in den anderen Funktionssystemen führen. Divergenzen in der Interpretation zwischen Kodex- und Verbandsystem müssen vom Recht gelöst werden. Das Problem stellt sich immer dann, wenn das Kommunikationssystem Kodex von einem bestimmen Mindestinhalt der Umsetzungsmaßnahmen ausgeht und das Kommunikationssystem Verband von dieser Einschätzung abweicht. Dann muss das Kommunikationssystem Recht entscheiden, ob das Organ gegen $\$ 161$ AktG verstoßen hat, indem es diese Abweichung nicht offen gelegt hat. Die strukturellen Kopplungen erlauben drei unterschiedliche Operationen (1.) Das Recht rezipiert die

278 Siehe Deilmann/Albrecht, AG 2010, 727, 729 f; Henze/Rosch, ArbRAktuell 2010, 573; Weber-Rey/ Handt, NZG 2011, 1, 3; iE auch Hecker/Peters, BB 2010, 2251, 2254.

279 Deilmann/Albrecht, AG 2010, 727, 729 f; Henze/Rosch, ArbRAktuell 2010, 573; Mense/Rosenhäger, GWR 2010, 311; Schulz, BB 2010, 2390, 2391; Schubert/Jacobsen, WM 2011, 726, 729; zurückhaltender Dauner-Lieb, DB 2010, 45, 46; Weber-Rey/Handt, NZG 2011, 1, 3.

280 Vgl. EuGH Urt. v. 28.3.2000, Rs. C-158/97 - Badeck, Slg. 2000, I-1875.

281 Ein Formulierungsvorschlag dazu bei Schulz, BB 2010, 2390, 2393.

282 Vgl. Keiluweit, DStR 2010, 2251, 2252.

283 Schubert/Jacobsen, WM 2011, 726, 730.

284 Dazu Hüffer, AktG (Fn 119), \$161 Rn. 20.

285 Weber-Rey/Handt, NZG 2011, 1, 3.

286 Eingehend Schubert/Jacobsen, WM 2011, 726, 729. 
Auffassung des Kodex. (2.) Das Recht teilt die Einschätzung des Verbandes. (3.) Das Recht entwickelt seinen eigenen Begriffsinhalt.

Die erste Auffassung stärkt die Definitionshoheit des Kodex. Erklärt sich der Verband nicht anderweitig, geht das Recht davon aus, dass er den so konzipierten Inhalt auch im eigenen Subsystem übernommen hat. Kommt er dem nicht nach, verletzt er \$ 161 AktG. Dann kommt es zu Sanktionen im Rechtssystem. ${ }^{287}$ Die dogmatischen Instrumente dafür sind Nichtigkeit bzw. Anfechtbarkeit der Entscheidungen der Verbandsorgane. Dazu zwei Beispiele: Unterbreitet der Aufsichtsrat der Hauptversammlung einen Beschlussvorschlag, der inhaltlich im Widerspruch zu den KodexEmpfehlungen steht, ist er aus $\mathbb{\$} 161 \mathrm{AktG}$ verpflichtet, die geänderte Absicht gleichzeitig mit dem Beschlussvorschlag bekannt zu machen. ${ }^{288}$ Ansonsten ist der Wahlvorschlagsbeschluss nichtig ${ }^{289}$ und der darauf basierende Hauptversammlungsbeschluss anfechtbar. ${ }^{290}$ Anders entscheidet man bei der Vorstandsbestellung. Weicht der Aufsichtsrat ohne Offenlegung von seiner Entsprechenserklärung ab, bleibt der Beschluss wirksam. ${ }^{291}$ Der Unterschied wird mit dem Schutzzweck des $\mathbb{S} 161 \mathrm{AktG}$ erklärt. ${ }^{292}$ Überzeugender ist es, das Problem auf die Definitionshoheit zurückzuführen. Im ersten Fall beansprucht sie der Kodex für sich und das Recht räumt sie ihm auch ein. Im zweiten Fall weist der DCGK dem Verband die Definitionskompetenz darüber zu. ${ }^{293}$ Diesbezüglich hat der Verband seine autonome Zielsetzung nicht offenzulegen. Weicht er von ihr ab, ist der Kodex nicht irritiert. Das Recht akzeptiert diese Arbeitsteilung.

Entscheidet sich das Recht dagegen für die zweite Konstellation, läuft die vom DCGK angestrebte Steuerung der Verbandssysteme leer. Der Aufsichtsrat unterbreitet beispielsweise einen Wahlvorschlag, ohne eine konkrete Zielvorgabe zum Frauenanteil beschlossen zu haben. Damit genügt er nicht den vom Kodex aufgestellten Mindestanforderungen an das „Wie“.294 Teilt das Rechtssystem diese Auffassung nicht, verstößt der Verband nicht gegen $\mathbb{} 161$ AktG, wenn er vom Begriffsverständnis im System des Kodex abweicht. Das ist die Folge der operativen Geschlossenheit des Rechts. Der Begriff der „Empfehlungen“ in $\mathbb{} 161$ Abs. 1 AktG erlaubt zwar eine zyklische

287 Zu den Rechtsfolgen ausführlich Deilmann/Albrecht, AG 2010, 727, 731; Schubert/Jacobsen, WM 2011, 726, 730 ff; siehe auch Kocher, BB 2010, 264, 266.

288 Grundlegend BGHZ 180, 9, Rn. 19; OLG München NZG 2009, 509, 510; näher Sester in: Spindler/ Stilz, AktG, $\mathbb{1} 161$ Rn. 50 ff ; Spindler in: Schmidt/Lutter, AktG, $\mathbb{1 6 1}$ Rn. 43 f.

289 OLG München NZG 2009, 509, 510.

290 Str, siehe OLG München NZG 2009, 509, 510; LG Hannover NZG 2010, 744748; zum Streitstand mit Blick auf die Diversity-Empfehlungen näher Deilmann/Albrecht, AG 2010, 727, $731 \mathrm{ff}$; Schubert/ Jacobsen, WM 2011, 726, $732 \mathrm{ff}$.

291 Näher Kocher, BB 2010, 264, 266; Schubert/Jacobsen, WM 2011, 726, 734.

292 Vgl. OLG München NZG 2009, 509, 510 und Schubert/Jacobsen, WM 2011, 726, 734.

293 S.o. IV 3 a) (2) bb).

294 S.o. IV 3 a) (2) cc). 
Verknüpfung mit dem Kodex, überlässt die Ausfüllung des Begriffs aber den internen Operationen des Rechts.

Die dritte Entscheidungsvariante erlaubt es dem politischen System, das Recht zu instrumentalisieren, um über $\mathbb{} 161 \mathrm{AktG}$ das Ziel der Geschlechtergerechtigkeit schneller durchzusetzen. Anknüpfungspunkt für diese Operation ist beispielsweise der Begriff der Angemessenheit. Exemplarisch für diese Instrumentalisierung ist die These, der Verband solle „die externen Erwartungen an eine angemessene Höhe des Frauenanteils im Aufsichtsrat, insbesondere im politischen Raum “295 berücksichtigen. Die Entscheidungskompetenz darüber liegt nach der vom Kodex vorgenommen Arbeitsteilung beim Aufsichtsrat. Teilt er diese Einschätzung, akzeptiert das Recht seine unternehmerische Entscheidung, solange er dabei vernünftigerweise annehmen durfte, auf Grundlage angemessener Informationen zum Wohle der Gesellschaft zu handeln $(\mathbb{S} \$ 116$ S. $1 \mathrm{iVm} \mathbb{S} 93$ Abs. 1 S. 2 AktG). Zur Instrumentalisierung des Rechts kommt es, wenn der Aufsichtsrat diese Einschätzung nicht teilt und das Recht bei der Interpretation des $\mathbb{1 6 1} \mathrm{AktG}$ die politische Zielsetzung als dem Kodex inhärent unterstellt. Dann wäre eine nicht erklärte Abweichung ein Verstoß gegen $\$ 161$ AktG. Dagegen muss man im Rechtssystem darauf insistieren, dass es auch hier die Entscheidungskompetenz des Aufsichtsrats akzeptiert. Der DCGK hat die Definitionshoheit über diese Frage an den Verband delegiert. Die zwischen DCGK und Verband vorgenommene Arbeitsteilung hat das Recht zu respektieren.

Zusammenfassend zeigt sich, dass die Steuerungsfähigkeit des DCGK entscheidend von drei Faktoren abhängt: (1.) den vom DCGK aufgestellten Mindestanforderungen einer compliance und (2.) der Bereitschaft des Rechts, diese Mindestanforderungen bei der Interpretation des $\ 161$ AktG zugrunde zu legen und (3.) der Nicht-Bereitschaft von Unternehmen, eine Abweichung von den Empfehlungen mit Mindestinhalt zu erklären und zu begründen.

\section{(3) Persistenz statussichernder Ungleichbehandlung}

Bedingung erfolgreicher Selbstregulierung ist es, dass sich die Ziele der Regelsetzung und die Interessen der Beteiligten bzw. der von der Regel Betroffenen weitgehend decken. ${ }^{296}$ Systemtheoretisch formuliert, muss das Ziel der Geschlechtergerechtigkeit über strukturelle Kopplungen in das Wirtschaftssystem und dessen Subsystemen die Verbände - „übersetzt“ werden. Diese Aufgabe übernimmt der Business Case für Diversity. Er ermöglicht es, eine moralisch-politische Frage von Gleichberechtigung an den im Wirtschaftssystem geltenden Code anzuknüpfen. ${ }^{297}$ Der Ansatz steht bei

295 Ringleb/Kremer/Lutter/Werder, NZG 2010, 1161, Rn. 1025 h.

296 Vgl. Buck-Heeb/Dieckmann, Selbstregulierung im Privatrecht, 2010, 243.

297 Zur Kritik dieser Instrumentalisierung aus feministischer Perspektive Andresen/Koreuber, Einführung, in: Andresen/Koreuber/Lüdke, Gender oder Diversity: Alptraum oder Traumpaar?, 2009, 19 ff; Krell, FS Heide Pfarr, 2010, 149 ff. 
Gleichbehandlungsfragen aber auf unsicherem Grund. ${ }^{298}$ Als marktbezogener Lösungsansatz kann er das strukturelle Problem präferenzbedingter Diskriminierung nicht ausreichend - vor allem nicht ausreichend schnell - adressieren. Die These, dass der informierte Kapitalmarkt Anreize bietet, die zur Steigerung des Frauenanteils beitragen, ist - um es vorsichtig zu formulieren - fraglich. Eine aktuelle Untersuchung der Auswirkungen von Frauen im Board von 432 U.S.-amerikanischen Unternehmen im Zeitraum von 1997-2006 kam zum überraschenden Ergebnis, dass die Besetzung mit Frauen negative Auswirkungen auf den Börsenwert des Unternehmens hatte. ${ }^{299}$ Die Autoren der Studie erklären das mit einer negativen Präferenz institutioneller Investoren: „Because investors are not accustomed to thinking of women as board members and tend to believe that women lack the human capital and business experience to be board members, we posit that institutional investors may react negatively to firms that appoint women board members. "300 Damit greifen sie auf Erklärungsmuster in der sozialen Kognitionstheorie zurück, nach denen wir die Unterscheidung zwischen „uns“ und den „,anderen“ als soziale Kategorisierung benutzen und mit unseren tatsächlichen oder stereotypen Erfahrungen verbinden, um so ein Informationsdefizit auszugleichen. ${ }^{301}$ Die Studie bestätigt das Verständnis von Diskriminierung als sozialen Vorgang der Hierarchisierung. ${ }^{302}$

Das Merkmal „Geschlecht“ ist im Wirtschaftssystem ein Distributionsfaktor. Frauen sind im Wirtschaftssystem „weniger wert“. Der existierende gender pay gap in Führungspositionen ${ }^{303}$ ist ein Beispiel dafür, die Hartnäckigkeit, mit der sich der geringe Anteil von Frauen in Aufsichtsräten und Vorständen über so lange Zeit halten konnte und kann, ein anderes. „Die Reihen fest geschlossen, so lautet die Devise.“ ${ }^{304}$ Nach klassischer Auffassung müssten die mittel- und langfristig angenommenen ökonomischen Anreize dafür sorgen, dass diskriminierende Präferenzen vom Markt verdrängt werden. ${ }^{305}$ Paradoxerweise führen diese sozialen Praktiken zu ökonomischen Anreizen, ihnen zu folgen. ${ }^{306}$ Akteure im Wirtschaftssystem, die soziale Praktiken anderer Funktionssysteme durchbrechen, erleiden deshalb signifikante ökonomische

298 Weitere Kritik bei Hart, 92 J. of Business Ethics 585 (2010).

299 Dobbin/Jung, 89 N.C.L. Rev. 809 (2011).

300 Dobbin/Jung, 89 N.C.L. Rev. at 822.

301 Vgl. Fiske, 48 American Psychologist American Psychologist 621 (1993); Reskin, 29 Contemporary Sociology 319 (2000).

302 Vertiefend dazu Grünberger, Personale Gleichheit (Fn. 1), 459 ff.

303 Vgl. die empirischen Daten bei Holst/Busch, DIW Führungskräfte-Monitor 2010 (Fn. 2), 12 f, 47 ff; aus rechtlicher Sicht statt vieler Winter, Diskriminierungsfreie(re) Entgeltgestaltung - leider immer noch ein Prinzip ohne Praxis, FS Pfarr, 2010, 320 ff; ähnlich auch Langenfeld, DVBl. 2010, 1019, $1020 \mathrm{f}$.

304 Hohmann-Dennhardt, FS Pfarr, 2010, 235, 243.

305 Grundlegend Becker, The Economics of Discrimination (1957), 2nd ed., 1971, zur Kritik siehe Grünberger, Personale Gleichheit (Fn. 1), $1018 \mathrm{ff}$ mwN.

306 Zum Folgenden näher Grünberger, Personale Gleichheit (Fn. 1), 592 ff. 
Nachteile. ${ }^{307}$ Die existierenden sozialen Hierarchisierungsnormen bewirken damit ein Kartell der privilegierten Gruppenmitglieder und stellen sicher, dass einzelne Mitglieder nicht ausscheren. ${ }^{308}$ Der Zusammenhalt der Gruppe beruht auf einer dadurch sichergestellten Statuserzeugung: ${ }^{309}$ Gruppen, die sich nach sozialen Kriterien organisieren und unterscheiden, bilden eine zentrale Quelle von Anerkennung für diejenigen, die dazu gehören. Gruppenmitglieder haben daher einen Anreiz, auf monetäre Gewinne zu verzichten, wenn sich dadurch ihr Status innerhalb der Gruppe verbessert. Als Netzwerkstrukturen innerhalb der Gesellschaft bestimmt sich der Status der jeweiligen Gruppe relativ zu anderen. Das führt zu Anreizen, den eigenen Gruppenstatus zu erhöhen und den anderer Gruppen zu minimieren. Der Business Case für Diversity blendet diese Zusammenhänge aus. Er operiert auf der Grundlage klassischer ökonomischer Theorien: „These explanatory frameworks assume fully rational actors making decisions based on careful calculations about a firm's current standing and future prospects. But in the stock market, as in other markets, behavior is shaped in important ways by psychological and sociological factors that these theories neglect. "310 Es ist daher zweifelhaft, ob man das Ziel der Geschlechtergerechtigkeit ausschließlich über den Weg des DCGK erreichen kann.

b) "FlexiQuote“

(1) Regulierte Selbstregulierung als Mehrstufenmodell

Diese Einschätzung teilt offensichtlich auch das politische System. Dort wird über eine Ergänzung und Alternative zum DCGK nachgedacht: die „FlexiQuote“.311 Nach dem Vorbild des aus der Wissenschaft stammenden Entwurfs eines Gesetzes zur Gleichstellung der Geschlechter in der Privatwirtschaft ${ }^{312}$ handelt es sich um ein Modell regulierter Selbstregulierung im Mehrstufensystem. Die „FlexiQuote“ ist der Name einer gesetzlichen Pflicht zur Selbstverpflichtung von Unternehmen. Börsennotierte und „voll mitbestimmte“ 313 Unternehmen sollen danach gesetzlich verpflichtet werden, eine selbst bestimmte und unternehmensspezifisiche Frauenquote für Aufsichtsrat und Vorstand festzulegen und zu veröffentlichen, die innerhalb einer ebenfalls selbst bestimmten Frist erreicht werden soll. Verfehlt ein Unternehmen die selbstgesetzten Ziele, sollen "gesellschaftsrechtliche Sanktionen (Anfechtbarkeit etc. ) “ greifen. Erreicht es eine Quote von $30 \%$ in Vorstand und Aufsichtsrat, entfällt

307 Akerlof, 90 Q.J. Econ. 599 (1976).

308 Vgl. Engert, 4 German L.J. 685692 (2003).

309 McAdams, 108 Harv. L. Rev. 1003 (1995),.

310 Dobbin/Jung, 89 N.C.L. Rev. 809, 838 (2011).

311 Siehe Schröder, Handelsblatt v. 28.1.2011, http://www.handelsblatt.com/ministerin-schroeder-willflexiquote-einfuehren/3817962.html; BMFSJF, Stufenplan „Frauen und Männer in Führungspositionen“ v. 6.6.2011, http://www.bmfsfj.de/BMFSFJ/gleichstellung,did=172756.html.

312 Pfarr (Hrsg.), Ein Gesetz zur Gleichstellung der Geschlechter in der Privatwirtschaft, 2001, 11 ff.

313 Daher ist zweifelhaft, ob auch Unternehmen nach dem DrittelbG erfasst sind; allgemein zum Kreis potentieller Regulierungsadressaten Langenbucher, JZ 2011, 1038, $1039 \mathrm{ff}$. 
die Pflicht zur Quote. Die „FlexiQuote“ soll mit einer aufschiebenden Bedingung verknüpft werden. Danach tritt sie nur in Kraft, wenn es der Wirtschaft insgesamt bis zu einem Zeitpunkt in 2013 nicht gelungen sein sollte, den durchschnittlichen Frauenanteil in Aufsichtsräten und Vorständen zu verdreifachen.

Indem das Modell eine gesetzliche Pflicht zur autonomen Quotenfestlegung anordnet, holt es sich zwangsläufig alle Regelungsprobleme eines gesetzlichen Quotenmodells ins Haus. Das gilt insbesondere für das Gleichheitsparadoxon. ${ }^{314}$ Aus unionsrechtlicher Sicht ist es unerheblich, ob der Staat die Quote vorgibt oder ob er den Unternehmen vorgibt, sich selbst eine Quote zu geben. In beiden Fällen stellen sich dieselben Rechtfertigungsfragen. Das gilt im Wesentlichen auch für die verfassungsrechtliche Dimension des Problems. Das Modell einer „FlexiQuote“ erfordert lediglich eine differenzierte Konstruktion des staatlichen Eingriffs in das Gleichheitsgrundrecht. ${ }^{315}$ Unterschiedlich kann allerdings die Verhältnismäßigkeitsprüfung innerhalb der Freiheitsrechte ausfallen, weil die Festlegung der Höhe der Quote den Unternehmen selbst überlassen bleibt. Nicht überzeugen kann das Argument, die „FlexiQuote“ sei im Vergleich zur Einheitsquote schon grundsätzlich das mildere Mittel. Man kann nämlich mit guten Gründen darüber streiten, ob sie zur Verwirklichung des Ziels der Geschlechtergerechtigkeit gleich geeignet ist. ${ }^{316}$

\section{(2) Eingeschränktes Misstrauensvotum gegenüber dem DCGK}

Mit der „FlexiQuote“ droht der Gesetzgeber, „die Sache wieder an sich zu ziehen und da, wo er den Kodex für nicht ausreichend hält oder seine Akzeptanz durch die Unternehmen nicht ausreicht, ein Gesetz zu erlassen“.317 Die Diversity-Empfehlungen des DCGK sind darin lediglich eine Vorstufe zur gesetzlichen Regelung. Mit der „FlexiQuote“ ginge der Gesetzgeber darüber hinaus: (1.) Der Verband muss sich eine Quote für die Besetzung des Aufsichtsrats geben. Zu diesem Ergebnis kommt man beim Kodex nur mit einer entsprechenden Interpretation der Empfehlung. ${ }^{318}$ (2.) Der Verband muss sich eine Quote für den Vorstand setzen. Damit weicht der Vorschlag deutlich von der im Kodex vorgenommenen Kompetenzverteilung zugunsten der Präferenzautonomie des Verbandes ab. ${ }^{319}$ (3.) Als Instrument staatlicher Regulierung entfällt für den Verband die Möglichkeit des opt-out. Eine gesetzlich vorgeschriebene Pflicht zur Festlegung einer Frauenquote muss das Kartellverhalten der

314 Oben IV 2 b. Irreführend daher die Aussage der BM Schröder (Fn. 311), differenzierter dagegen Ossenbühl, NJW 2012, 417, 420 ff. [Der Beitrag beruht - was in der NJW nicht offengelegt wird auf einem Rechtsgutachten, das Ossenbühl im Januar 2011 im Auftrag des BMFSFJ erstattet hat.]

315 Eingehend Sachs, ZG 2012 (Heft 1) unter II 2 d.

316 Spindler/Brandt, NZG 2011, 401, 404 halten die „FlexiQuote“ für ungeeignet; kritisch auch Bachmann, ZIP 2011, 1131, $1133 \mathrm{f}$.

317 Seibert, BB 2002, 581, 582.

318 S. o. IV 3 a) (2) cc).

319 S. o. IV 3 a) (2) bb). 
Akteure $^{320}$ adressieren, indem es die Einhaltung sozialer Praktiken zur Statussicherung verteuert. Daran haben sich die Rechtfolgen jedes gesetzlichen Quotenmodells zu orientieren. Ein Beispiel dafür ist das französische Recht, das dem nicht gesetzeskonform besetzten Aufsichtsrat die Bezüge suspendiert. ${ }^{321}$

Die Politik hat ihr Misstrauensvotum gegenüber dem Kodex allerdings zeitlich suspendiert, wie die Idee des aufschiebend bedingten Inkrafttretens zeigt. Den Diversity-Empfehlungen wird damit eine Gnadenfrist eingeräumt. Diese läuft nicht zufällig nach den im Jahr 2013/14 turnusgemäß gehäuft auftretenden Aufsichtsratswahlen ab. Damit baut das politische System eine Drohkulisse für börsennotierte und mitbestimmte Gesellschaften auf, den Diversity-Empfehlungen des DCGK ${ }^{322}$ zu folgen. Diese Operation des politischen Systems führt zu Irritationen in den anderen Funktionssystemen: Die Suspension lässt sich nur mit der Annahme des politischen Systems erklären, dass dem DCGK jedenfalls für den Aufsichtsrat ein Zwang zu entnehmen ist, eine signifikante Quote festzulegen. Der Kodex kann diese Annahme im Begriff der „Angemessenheit“ aufgreifen, wenn man diesen Begriff auch auf Erwartungen der Umwelt an das Funktionssystem erstreckt. ${ }^{323}$ Dadurch - und das muss man hervorheben - wird der DCGK politisch instrumentalisiert. Die Aussage, dass eine gesellschaftspolitische Besserstellung von Frauen nie Ziel der Empfehlungen war, ${ }^{324}$ wird damit unhaltbar. Im Gegenteil: Die Diversity-Empfehlungen müssen angesichts der beschränkten Fähigkeit des Business Case bewusst als Maßnahmen zur Herstellung von Geschlechtergerechtigkeit konzipiert werden, um einer gesetzlichen Regelung zuvorzukommen. ${ }^{325}$ Das bleibt nicht ohne Auswirkungen auf die Interpretation des $\$ 161 \mathrm{AktG}$. Unternehmen, die keine konkrete Quote als Zielvorgabe nennen, weichen dann von der Diversity-Empfehlung ab und müssen dies offenlegen. ${ }^{326}$ Diese Offenlegung steht den Unternehmen als realistische Option aber nicht mehr zur Verfügung. Machen sie nämlich vermehrt davon Gebrauch, aktiviert das genau den Misstrauensmechanismus, der dem Modell der „FlexiQuote“ eingebaut ist. Der tragende Gedanke des DCGK - comply or explain - wird damit desavouiert. ${ }^{327}$ Es heißt jetzt: Comply or we'll force you to comply.

320 S. o. IV 3 a (3).

321 S.o. IV 2 a).

322 Zum potentiellen Adressatenkreis des DCGK näher Ringleb in: Ringleb/Kremer/Lutter/Werder, DCGK (Fn. 231), Vorbem. Rn. $128 \mathrm{ff}$.

323 S.o. IV 3 a) (2) cc).

324 Weber-Rey/Handt, NZG 2011, 1, 2, dazu bereits unter I.

325 Vgl. Ringleb/Kremer/Lutter/Werder, NZG 2010, 1161, Rn. 1025 hf.

326 Vgl. dazu Langenbucher JZ 2011 1038, 1043.

327 Vgl. zum ähnlichen Problem der Vorstandsvergütung Spindler, NZG 2005, 689, 692. 


\section{Ein Kombinationsmodell}

Nach traditionellem Verständnis verhindert eine „gläserne Decke“, dass Frauen in Führungspositionen, von dort in den Vorstand und von dort in den Aufsichtsrat kommen. ${ }^{328}$ Man kann den Zusammenhang aber auch umkehren und „vom Kopf her denken“. ${ }^{329}$ Danach ist es gerade die Männerdominanz in Aufsichtsrat und Vorstand, die zum status quo im Vorstand bzw. auf den Führungsebenen beiträgt. Dafür spricht das Modell statussichernder Hierarchisierung. ${ }^{330}$ Eine Quotenregelung für den Aufsichtsrat hat das Potential, diesen Zusammenhang zu durchbrechen und die „gläserne Decke“ von oben zu durchstoßen. Das wird sie als Einzelmaßnahme nicht schaffen. Darunter leidet die gegenwärtige Debatte. Sie behandelt die verschiedenen Lösungswege als Alternativen. Nach meiner Auffassung ist ein kombinatorischer Ansatz notwendig, der alle Ebenen des Unternehmen im Blick hat. Ziel ist es, mit einen top-down-Ansatz ausreichend Möglichkeiten zu schaffen, damit Frauen von unten in Führungspositionen aufsteigen können. Die auf mehreren Unternehmenshierarchiestufen angesiedelten Diversity-Empfehlungen des DCGK ${ }^{331}$ erkennen diesen Zusammenhang im Ansatz. Will man Geschlechtergerechtigkeit in Unternehmen erreichen, halte ich es für notwendig, die verschiedenen Regulierungsansätze zu kombinieren und auf allen Ebenen differenziert einzusetzen. Das AGG als Element staatlicher Regulierung erfasst jede Ebene, berücksichtigt aber nur individuelle Ungleichbehandlungen auf dem Weg nach oben. Für den Aufsichtsrat konkurrieren Einheits- oder „FlexiQuote“ um den rechtspolitischen Vorzug. Unter unions- und verfassungsrechtlichen Gesichtspunkten sind beide Instrumente möglich. ${ }^{332}$ Der entscheidende Vorteil der „FlexiQuote“ liegt darin, dass sie die Eigenrationalität des Verbandes stärker respektiert und auf dem im jeweiligen Funktionssystem gesammelten Wissen aufbaut. Ihr Nachteil ist es, dass die Durchsetzung von Geschlechtergerechtigkeit zeitlich weiter verzögert wird. Beim Aufsichtsrat präferiere ich daher eine gesetzliche Einheitsquote nach französischem Muster. Dafür spricht seine Konzeption als Gremium, das sich durch Vielfältigkeit auszeichnet. Diese Vielfältigkeit lässt sich mit Frauen und Männern gemeinsam abbilden. Anders ist für den Vorstand zu entscheiden. Hier kann die „FlexiQuote“ ihren Vorteil ausspielen. Der damit verbundene Nachteil ist von Politik und Recht zu akzeptieren, damit die strukturellen Kopplungen nicht überstrapaziert werden. Daneben bleibt Raum für neugefasste Diversitätsempfehlungen im DCGK. Der Kodex könnte beispielsweise vorsehen, dass in allen Ausschüssen des Aufsichtsrats, die sich mit Personalfragen beschäftigen („findig committee“), Frauen angemessen zu beteiligen sind. Dasselbe gilt für die

328 Vgl. Holst/Busch, DIW Führungskräfte-Monitor 2010 (Fn. 2), 55 ff.

329 Hohmann-Dennhardt, FS Pfarr, 2010, 235, 246.

330 S. o. IV 3 a) (3).

331 S.o. IV 3 a) (2).

332 Papier/Heidebach, ZGR 2011, 305, 313 ff, 329 ff; aA insbesondere Sachs, ZG 2012 (Heft 1) unter II. 
Vorstandsebene. Die Empfehlung zur Förderung von Frauen in Führungspositionen unterhalb des Vorstands sollte im Kodex schärfer formuliert werden. Der Vorstand sollte ausdrücklich aufgefordert werden, dieses Ziel mit konkreten positiven Maßnahmen zu erreichen. Diese sind auf allen Unternehmenshierarchien umzusetzen.

\section{Ausblick}

Die Debatte zu Frauenquoten in Aufsichtsrat und Vorstand ist einzubetten in den größeren Zusammenhang von Frauen in Führungspositionen und in den Komplex der Entgeltgleichheit unabhängig vom Geschlecht und der Vereinbarkeit von Familie und Beruf. ${ }^{333}$ Dass sie mit dieser Intensität geführt wird, ist Ausdruck eines gesellschaftlichen Unbehagens, das aus der vom Wirtschaftssystem ausgehenden „Kolonisierung der Lebenswelten“ (Habermas) herrührt. Die Gestaltung der Arbeitsbedingungen und die Auslagerung familiärer Pflichten stellen sicher, dass Zugangsbarrieren für Frauen und Männer errichtet werden, die ein anderes Lebensmodell verfolgen. ${ }^{334}$ Die Unterrepräsentanz von Frauen im Vorstand lässt sich dann ganz einfach damit erklären, „dass viele Frauen den entbehrungsreichen Weg ins Top-Management gar nicht erst antreten wollen “. ${ }^{335}$ Dabei wird ausgeblendet, dass es für die Männer in den Positionen normal ist, eine intakte Familie zu haben. ${ }^{336}$ Das ist mit den Leistungsanforderungen „natürlich“ nur dann vereinbar, wenn man diese Aufgabe auf die Ehefrau delegieren kann. Mit den auf Gewinnmaximierung beruhenden Arbeitsstrukturen und den daraus resultierenden Anpassungsanforderungen des Einzelnen expandiert das ökonomische Denken in andere Funktionsbereiche der Gesellschaft. Das Recht kann dem Grenzen setzen, wenn es die in ihm angelegte Forderung nach Geschlechtergerechtigkeit ernst nimmt. Der Topos ermöglicht es dem Recht, den Sozialeffekt privatrechtlicher Institutionen wie der Verbandsautonomie in der Umwelt des Rechts wahrzunehmen. ${ }^{337}$ Die über den Begriff erreichte Sensibilisierung des Rechts für seine Umwelt stellt sicher, dass es seine Leistungen allen betroffenen Funktionssystemen - Wirtschaft, Familie, Person - gleichermaßen und neutral anbieten kann. ${ }^{338}$ Das Argument aus der Geschlechtergerechtigkeit kann natürlich keine „gerechte“ Gesellschaft mit den Mitteln juristischer Gerechtigkeit allein errichten. Damit würde man den Imperialismus der Wirtschaft mit dem des Rechts austreiben und „ein falsches Heilversprechen“ abgeben. ${ }^{339}$ Es kann aber dazu

333 Dazu zuletzt Langenfeld, DVBl. 2010, 1019, $1025 \mathrm{ff}$.

334 Vgl. Hohmann-Dennhardt, FS Pfarr, 2010, 235, 243 f; ähnlich die Einschätzung zum Wissenschaftssystem bei Langenfeld, DVB1. 2010, 1019, $1021 \mathrm{f}$.

335 Bachmann, ZIP 2011, 1131, 1139.

336 Siehe die Untersuchung von Wipperman, Frauen in Führungspositionen - Barrieren und Brücken (Fn. 147), $47 \mathrm{ff}, 64 \mathrm{f}$.

337 Vgl. Wielsch, Iustitia mediatrix: Zur Methode einer soziologischen Jurisprudenz, FS G. Teubner, 2009, 395, 411.

338 Vgl. Wielsch, FS G. Teubner, 2009, 395, 411.

339 Siehe Teubner, ZfRSoz 2008, 9, 32 f. 
beitragen, die Eigenrationalität des Rechts unter Respektierung der Eigenrationalitäten der anderen Funktionssysteme angemessen zu erfassen. ${ }^{340}$ Diese Zusammenhänge zu erkennen und als erlaubte rechtliche Operation zu beschreiben, ist Aufgabe einer Theorie juristischer Gerechtigkeit als Gleichheit. ${ }^{341}$

340 Näher Teubner, Altera pars audiatur: Das Recht in der Kollision anderer Universalitätsansprüche, in: Pawlowski/Roellecke (Hrsg.), Der Universalitätsanspruch des demokratischen Rechtsstaats (ARSP Beiheft 65), 1996, 199 ff.

341 Ein Modell für das Gleichbehandlungsrecht hat Grünberger, Personale Gleichheit (Fn. 1), 940 ff, $948 \mathrm{ff}$, vorgelegt. 